ARTICLE

DOI: $10.1038 / s 41467-017-01547-8$

\title{
Antagonistic bacteria disrupt calcium homeostasis and immobilize algal cells
}

\author{
Prasad Aiyar ${ }^{1}$, Daniel Schaeme ${ }^{1}$, María García-Altares ${ }^{2}$, David Carrasco Flores ${ }^{1}$, Hannes Dathe ${ }^{1}$ \\ Christian Hertweck (i) ${ }^{2}$, Severin Sasso ${ }^{1} \&$ Maria Mittag (i) ${ }^{1}$
}

Photosynthetic unicellular organisms, known as microalgae, are key contributors to carbon fixation on Earth. Their biotic interactions with other microbes shape aquatic microbial communities and influence the global photosynthetic capacity. So far, limited information is available on molecular factors that govern these interactions. We show that the bacterium Pseudomonas protegens strongly inhibits the growth and alters the morphology of the biflagellated green alga Chlamydomonas reinhardtii. This antagonistic effect is decreased in a bacterial mutant lacking orfamides, demonstrating that these secreted cyclic lipopeptides play an important role in the algal-bacterial interaction. Using an aequorin $\mathrm{Ca}^{2+}$-reporter assay, we show that orfamide $A$ triggers an increase in cytosolic $\mathrm{Ca}^{2+}$ in $\mathrm{C}$. reinhardtii and causes deflagellation of algal cells. These effects of orfamide $A$, which are specific to the algal class of Chlorophyceae and appear to target a $\mathrm{Ca}^{2+}$ channel in the plasma membrane, represent a novel biological activity for cyclic lipopeptides.

\footnotetext{
${ }^{1}$ Institute of General Botany and Plant Physiology, Friedrich Schiller University, Am Planetarium 1, 07743 Jena, Germany. ${ }^{2}$ Leibniz Institute for Natural Product Research and Infection Biology (HKI), Beutenbergstr. 11 a, 07745 Jena, Germany. Correspondence and requests for materials should be addressed to S.S. (email: severin.sasso@uni-jena.de) or to M.M. (email: M.Mittag@uni-jena.de)
} 
arbon fixation by photosynthetic organisms is a crucial step in the global carbon cycle, converting $\mathrm{CO}_{2}$ and light into valuable, energy-rich organic molecules. Apart from higher plants, prokaryotic and eukaryotic microalgae in aquatic environments are responsible for approximately $50 \%$ of all carbon fixation annually ${ }^{1}$. In addition, these photosynthetic microorganisms are at the base of aquatic food webs, thus playing a key role in diverse ecosystems. In their freshwater and marine habitats, microalgae also naturally coexist with a large variety of other microorganisms. In analogy to the terrestrial plant environment, these complex interactions may influence the fitness and performance of the microalgae and even lead to their death. However, compared to the large body of knowledge on the effects of mutualists or parasites on higher plants ${ }^{2}$, there is limited information on biotic interactions of photosynthetic microbes. Only recently, an increasing number of studies were reported on
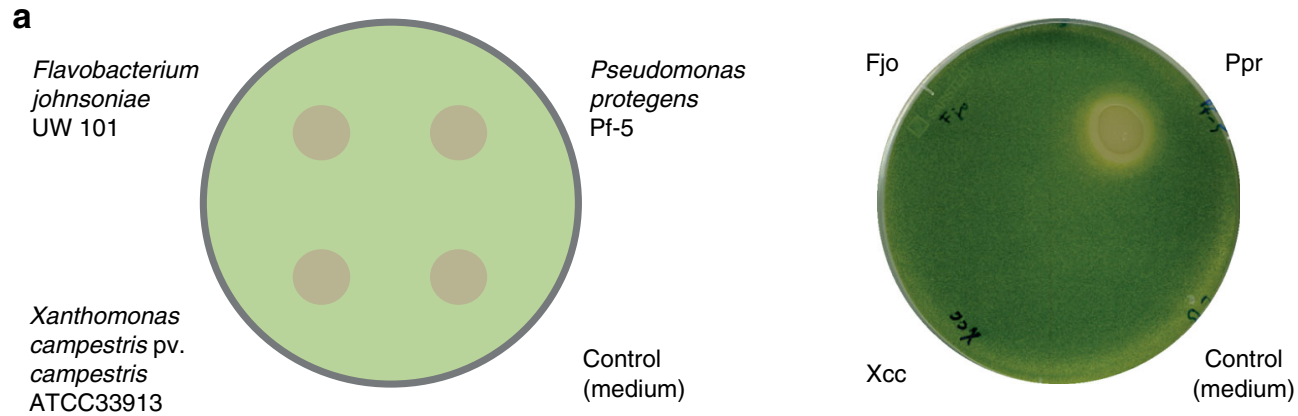

b

Inoculation ratio 1:1 (algae to bacteria)
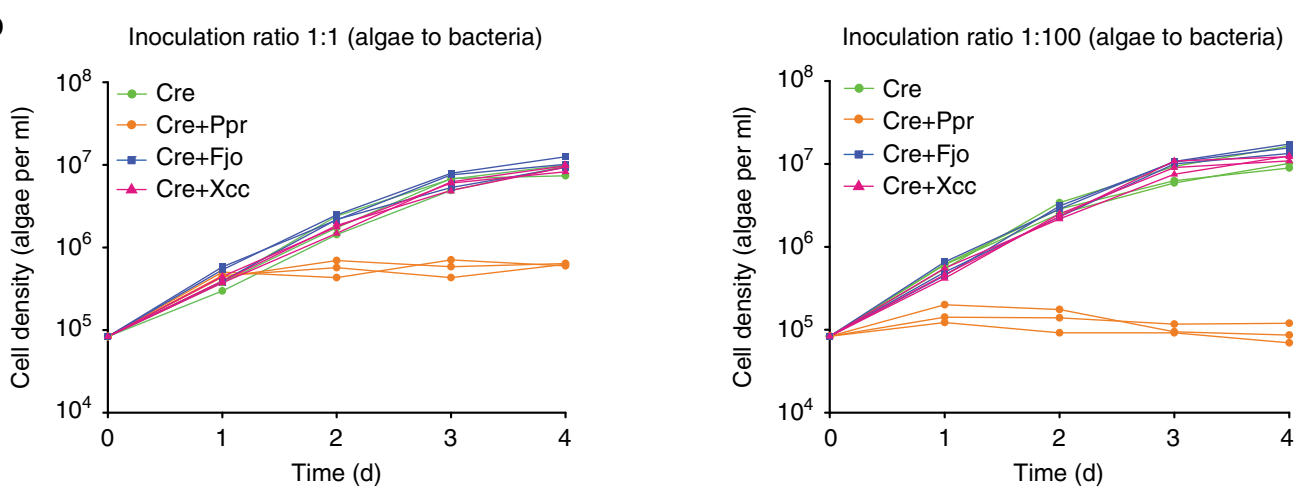

C

Cre

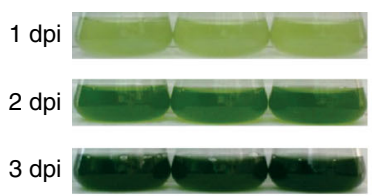

d

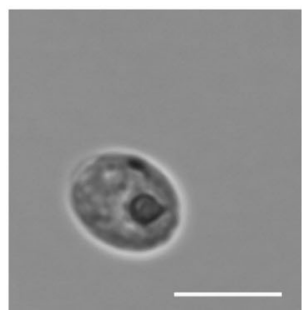

Cre

e

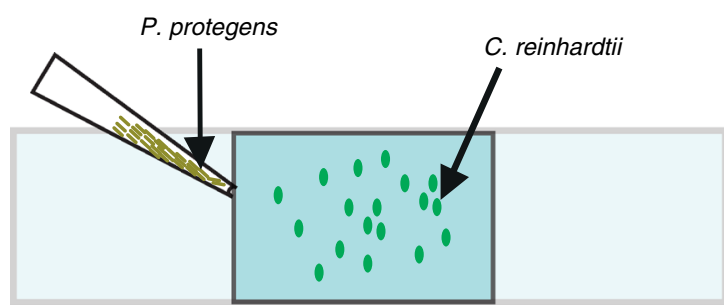

Supplemental Movie 1
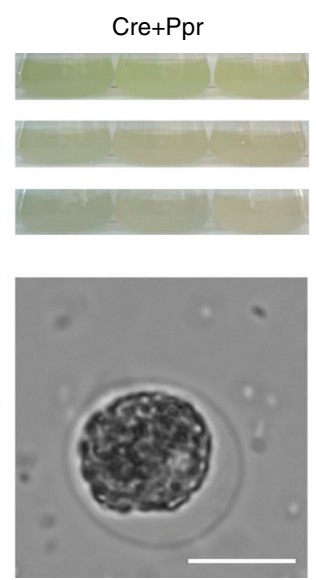

Cre+Ppr
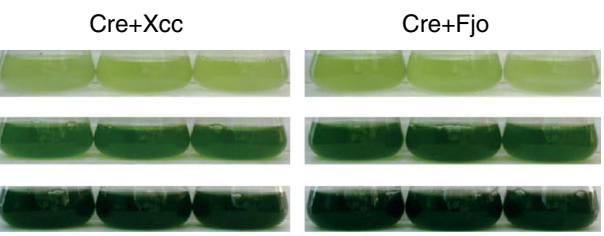

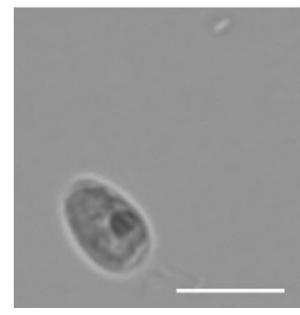

Cre+Xcc

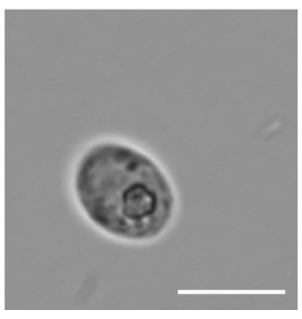

Cre+Fjo

f

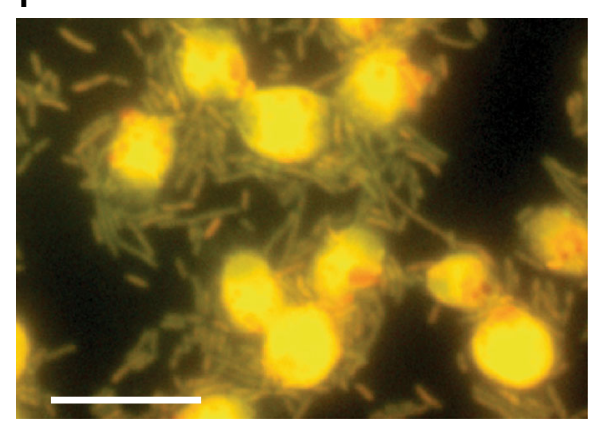


the characterization of algicidal bacteria and of natural products or enzymes that directly affect algal fitness ${ }^{3-7}$. In most cases, diffusible algicidal agents are secreted by the bacteria that inhibit cell growth, disrupt the cell envelope, and/or rapidly lyse target cells ${ }^{7}$. Other algicidal bacteria require direct contact with the algae to exert their destructive effects. In these cases, they employ enzymes to cleave polysaccharides or proteins that are present on the cell wall of the algae, thereby disrupting cell integrity and causing lysis ${ }^{7}$. However, most algicidal factors, their effects, and the involved signaling pathways remain to be elusive ${ }^{8}$. This lack of knowledge is surprising in light of the well-known relevance of microalgae for life on Earth and their emerging importance for biofuel production.

The poor knowledge on the mediators of microalgal-microbial communities may-at least in part-be attributable to the lack of interacting species that are genetically tractable. To evaluate the factors governing the interaction between bacteria and microalgae, we thus focused on a fully sequenced model organism, Chlamydomonas reinhardtii, for which molecular tools are available $^{9-11}$. This biflagellate unicellular green alga is ubiquitously distributed in habitats such as fresh water and moist soil, and has been extensively used to study light perception, photosynthesis, and flagellar function, and also with regard to human diseases $9,12,13$. However, C. reinhardtii is usually grown axenically in the laboratory, and only a few studies have explored how this algal genus responds to changes in biotic factors ${ }^{1-16}$. Here, we report on the biological function of secondary metabolites from the bacteria Pseudomonas protegens in their interplay with the motile microalga C. reinhardtii. P. protegens (formerly known as $P$. fluorescens $)^{19}$ also lives in aquatic and soil environments, where it either promotes plant growth ${ }^{18}$ or leads to the cell death of the photosynthetic organism ${ }^{3}$. By means of high-resolution mass spectrometry and a tailor-made reporter system, we found that $P$. protegens employs chemical mediators, including cyclic lipopeptides to deflagellate the $C$. reinhardtii cells and alter cytosolic $\mathrm{Ca}^{2+}$ levels. Immobilization and disruption of algal cells by $P$. protegens and its secondary metabolites appears to provide an advantage to the bacteria when deprived of micronutrients.

\section{Results}

$P$. protegens Pf-5 arrests the growth of $C$. reinhardtii. To investigate whether heterotrophic bacteria sharing the same habitat as C. reinhardtii affect algal growth, we selected Flavobacterium johnsoniae, Xanthomonas campestris pv. campestris, and $P$. protegens. Specifically, we used sequenced strains of bacterial species previously isolated from a microalgal culture ${ }^{14}$ and applied the bacteria to a restricted area on a plate that contains $C$. reinhardtii cells (Fig. 1a). In coculture with $F$. johnsoniae or $X$. campestris, the growth of $C$. reinhardtii appeared to be unaffected, i.e., comparable to that on the medium control. In contrast, $P$. protegens strongly inhibited the growth of $C$. reinhardtii. Likewise, in liquid cultures (inoculation ratio of 1:1 and 1:100 algae to bacteria), only $P$. protegens substantially decreased the cell density of $C$. reinhardtii compared to pure algal cultures (Fig. 1b). Algal growth was stopped within the first day in coculture (1:100 ratio) or starting 1 day after inoculation (1:1 ratio). Photographs taken of the cultures in a replete medium show that the typical green color of the algal culture is absent when cocultivated with $P$. protegens (1:100 ratio) (Fig. 1c), indicating the arrest of the algal growth. Furthermore, in contrast to the other bacteria, $P$. protegens altered the morphology of the algal cells within 1 day in coculture. The usually oval algal cells were enlarged and almost circular, and their inner structure became granular (Fig. 1d).

It is known that the depletion of micronutrients such as iron or zinc can affect the biocontrol properties of $P$. protegens ${ }^{19,20}$. To test whether $P$. protegens may benefit from $C$. reinhardtii under nutrient-limiting conditions, we omitted the trace elements $(\mathrm{Fe}$, $\mathrm{Zn}, \mathrm{Cu}, \mathrm{Co}, \mathrm{Mn}$, and $\mathrm{Mo}$ ) from the growth medium. While bacterial growth was largely unaffected in a replete medium (Supplementary Fig. 1a, b), it was enhanced in coculture in a medium lacking micronutrients, as compared to the axenic bacterial culture grown in the same medium (Supplementary Fig. 2a). Algal cells also showed an altered morphology after 1 day in coculture in the medium depleted of micronutrients, and they had lost their flagella (Supplementary Fig. 2b).

To learn more about the dynamics of the interaction of $C$. reinhardtii with $P$. protegens, we recorded a video (Supplementary Movie 1). Initially, the algal cells swim freely in the medium. After $19 \mathrm{~s}$, the bacteria were introduced from one corner of the slide (Fig. 1e). Within only $1.5 \mathrm{~min}$, the bacteria start to surround the algal cells that already appear to be immobilized. Two minutes later, the intensity of the swarming reaches a maximum, and algal cells are completely encircled by bacteria. The physical contact of the bacteria and the algae was independently confirmed using an acridine orange-stained fluorescent micrograph after a 10-min incubation time (Fig. 1f).

Orfamide A immobilizes several Chlorophyceae. $P$. protegens biosynthesizes a wide range of natural products, including medium-size molecular weight compounds such as polyketides and nonribosomal peptides ${ }^{21}$ that could have a role in the bacterial-algal interplay. To study the chemical mediators of the interaction, we monitored two-dimensional patterns of diffusible metabolites between mixed bacterial and algal cultures by MALDI-imaging mass spectrometry (MALDI-IMS) ${ }^{22-24}$. Organisms were directly grown on disposable indium tin oxidecoated glass slides that were overlaid with a layer of solidified growth medium (Supplementary Fig. 3a). These experiments

Fig. 1 P. protegens swarms to $C$. reinhardtii and leads to growth arrest and changes in algal morphology. a Co-cultivation of $C$. reinhardtii and bacteria on agar plates after 3 days reveals the inhibitory effect of $P$. protegens. Suspensions of different bacteria were applied to restricted areas of a plate that contains $C$. reinhardtii within a top layer of TAP agar. LB medium was used as control. $\mathbf{b}$ Liquid co-cultivation at indicated ratios of algae to bacteria used for inoculation shows algal growth arrest in the presence of $P$. protegens. Cultures were inoculated to obtain initial cell densities of $8.3 \times 10^{4}$ algae per ml, and in coculture $8.3 \times 10^{4}(1: 1)$ or $8.3 \times 10^{6}(1: 100)$ bacteria per $\mathrm{ml}$ were added. Values of triplicate cultures are shown. $\mathbf{c}$ Photographs of the experiment depicted in $\mathbf{b}$ (1:100 ratio) show algal growth arrest by the color change. $\mathbf{d}$ Morphology change of algal cells in the presence of $P$. protegens after $24 \mathrm{~h}$ in mixed culture as compared to an axenic culture by bright-field microscopy using a magnification of $\times 630$. Scale bar: $10 \mu \mathrm{m}$. e $P$. protegens swarms around the algal cells and surrounds them within minutes. Scheme depicting the experimental procedure used to visualize live interaction of $P$. protegens with $C$. reinhardtii

(Supplementary Movie 1). Overall, $10 \mu \mathrm{l}$ of an overnight culture of $P$. protegens in LB medium were introduced from one corner of the coverslip as shown in the scheme. $\mathbf{f}$ Cells of $C$. reinhardtii and $P$. protegens were immobilized after $10 \mathrm{~min}$ in coculture on a coated glass slide and stained with acridine orange. Cells were visualized using fluorescence microscopy at $\times 1000$ magnification. Scale bar: $10 \mu \mathrm{m}$. Cre Chlamydomonas reinhardtii, Fjo Flavobacterium johnsoniae, Xcc Xanthomonas campestris pv. campestris, Ppr Pseudomonas protegens, dpi days post inoculation. a-e All experiments were performed in three biological replicates and representative pictures (d) and a representative Supplementary Movie 1 are shown. $\mathbf{f}$ shows a representative section of an acridine orangestained sample as treated in e, but for $10 \mathrm{~min}$. The experiments were replicated three (a) or two times (e) or performed once (b, d) 
a XIC: $[\mathrm{M}+\mathrm{H}]^{+} \mathrm{m} / \mathrm{z} 1295.84744^{+} /-3 \mathrm{ppm}$ (int. of all peaks $\sim 6.00 \cdot 10^{7}$ )
MS/MS on $[\mathrm{M}+\mathrm{H}]^{+} \mathrm{m} / \mathrm{z}$ 1295.8, HCD 18\%, RT: 14.3-14.7 min
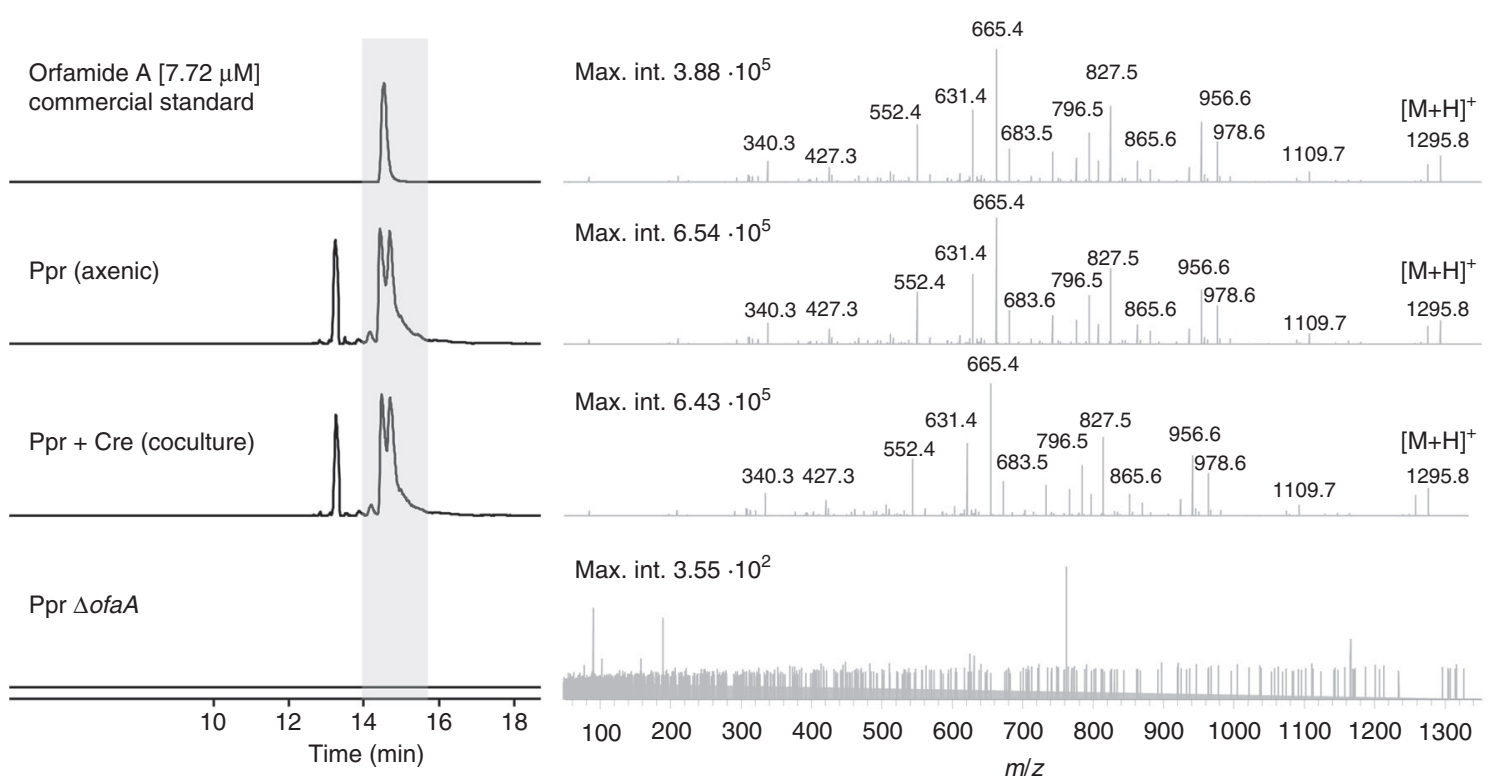

Max. int. $3.55 \cdot 10^{2}$

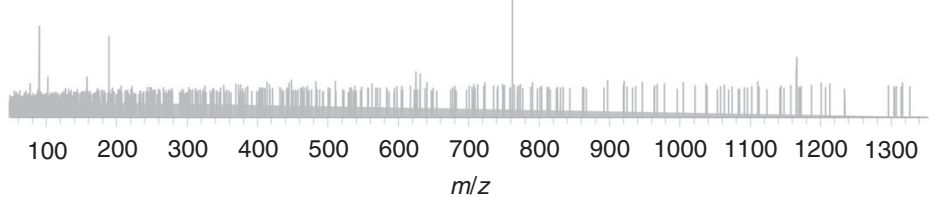

b

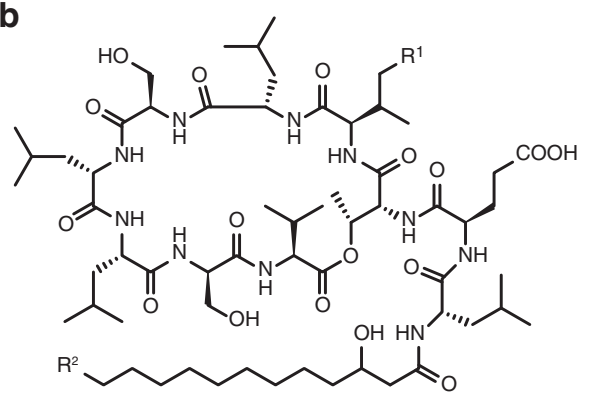

Orfamide $A: R^{1}=\mathrm{CH}_{3}, \mathrm{R}^{2}=\mathrm{C}_{2} \mathrm{H}_{5}$ Orfamide $B: R^{1}=H, R^{2}=\mathrm{C}_{2} \mathrm{H}_{5}$ Orfamide $C: \mathrm{R}^{1}=\mathrm{CH}_{3}, \mathrm{R}^{2}=\mathrm{H}$

C
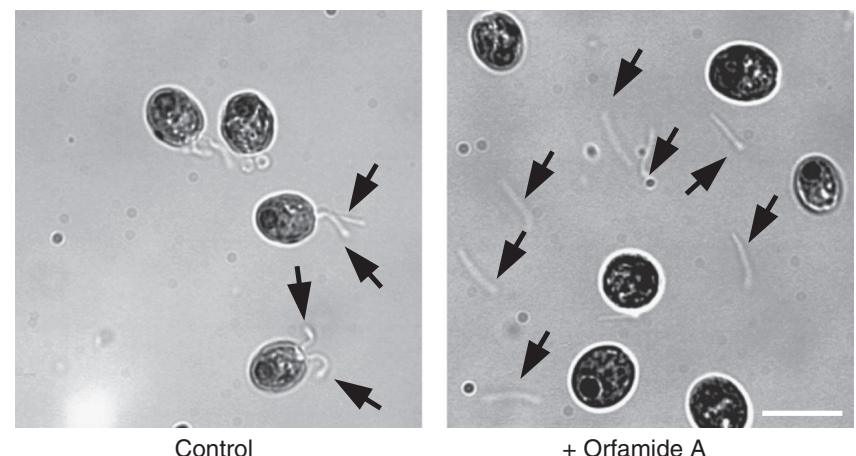

+ Orfamide A

Fig. 2 Orfamide $A$ is released by $P$. protegens and leads to deflagellation of the algal cells. a Detection of orfamide $A$ by high-resolution liquid chromatography-tandem mass spectrometry (LC-HRMS/MS). Extracted-ion chromatograms (XIC) of orfamide $A\left(\mathrm{C}_{64} \mathrm{H}_{114} \mathrm{~N}_{10} \mathrm{O}_{17}\right.$, accurate mass $1294.836345 \mathrm{u})[\mathrm{M}+\mathrm{H}]^{+} \mathrm{m} / \mathrm{z} 1295.8474 \pm 3 \mathrm{ppm}$ and its MS/MS fragmentation pattern are shown for orfamide A commercial standard and different extracts from culture supernatants including an extract of $P$. protegens in axenic culture, an extract of $P$. protegens in coculture with $C$. reinhardtii, and an extract of $P$. protegens $\triangle$ ofaA in axenic culture (orfamide deletion mutant). In MS/MS spectra, only the first decimal of $m / z$ values is shown to improve figure legibility. One independent experiment, with one biological replicate and two technical replicates was conducted. $\mathbf{b}$ Structures of orfamide A, B, and C. c Orfamide A deflagellates C. reinhardtii. Wild-type cells of $C$. reinhardtii were grown in TAP medium. A drop of $20 \mu$ l culture was applied on the slide. The cells were visualized in a bright-field microscope at $\times 200$ magnification (scale bar: $10 \mu \mathrm{m}$ ); the cell movement was recorded before and after application of $35 \mu \mathrm{M}$ orfamide $\mathrm{A}$ or methanol as control (Supplementary Movies 2-5). To visualize cells that retained or lost their flagella, cells were treated with orfamide A or methanol (control) for $30 \mathrm{~s}$, fixed with $8 \%$ potassium iodide and visualized using differential interference contrast (DIC) microscopy at $\times 630$ magnification. The orfamide and control treatments were done in biological triplicates (see also Supplementary Movies 2-5); a representative picture is shown. The experiment was replicated twice

revealed a cluster of very intense ions, in the range of $\mathrm{m} / \mathrm{z}$ $1300-1360$, localized mainly to the area surrounding the P. protegens growth (Supplementary Figs. $3 \mathrm{~b}$ and 4 ). To identify these ions, we analyzed extracts from culture supernatants of $P$. protegens grown axenically and in coculture with $C$. reinhardtii by liquid chromatography-high-resolution tandem mass spectrometry (LC-HRMS/MS). The ions detected by MALDI-IMS were also found in the extracts by LC-HRMS, and their exact masses fitted to the natural products orfamides (Fig. 2a; Supplementary Fig. 5). We used the commercial standard of orfamide $A$ as a reference and a $P$. protegens $\Delta o f a A$ mutant lacking all orfamides ${ }^{25}$ to confirm the identity of orfamide A (Fig. 2a). Orfamides B and
C were also detected in the extracts (Supplementary Fig. 5). Moreover, the extracted-ion chromatogram of $\mathrm{m} / z 1295.8474 \pm 3$ ppm (orfamide A $[\mathrm{M}+\mathrm{H}]^{+}$) showed two additional chromatographic peaks at different retention times compared to orfamide A (even when the mass tolerance window was reduced to $1 \mathrm{ppm}$ ), suggesting the presence of undescribed isomers of orfamide A in the extracts (Fig. 2a).

We next analyzed whether orfamide A (Fig. 2b) alone has an effect on the algal cells. A drop of $C$. reinhardtii cell suspension was placed on a glass slide, and a video was recorded before adding orfamide A or methanol (negative control), which were carefully applied from the top (Supplementary Movies 2- 


\section{Table 1 Loss of motility of exemplary flagellate algae upon treatment with orfamide $A$}

\begin{tabular}{llllll} 
Species & Class & Phylum & Habitat & Loss of motility & Supplementary videos \\
\hline Chlamydomonas reinhardtii & Chlorophyceae & Chlorophyta & FW/WS & Yes & $2-5$ \\
Chlamydomonas sp. & Chlorophyceae & Chlorophyta & Marine & Yes & 6,7 \\
Haematococcus pluvialis & Chlorophyceae & Chlorophyta & FW/WS & Yes & 8,9 \\
Gonium pectorale & Chlorophyceae & Chlorophyta & FW/WS & Yes & 10,11 \\
$\begin{array}{ll}\text { Pedinomonas minor } \\
\text { Euglena gracilis }\end{array}$ & Pedinophyceae & Chlorophyta & FW/WS & No & 12,13 \\
\hline FW Freshwater, ws wet soil & Euglenophyceae & Euglenophyta & FW/WS & No & 14,15 \\
Orfamide A was applied at a concentration of $35 \mu \mathrm{M}$ & & & \\
anon-axenic strain & & & & \\
\hline
\end{tabular}

a

\begin{tabular}{|lcc} 
HSP7OA/RBCS2 & Apo-aequorin & RACK1 \\
Tandem promoter & $\begin{array}{l}\text { Codon-optimized } \\
\text { synthetic gene }\end{array}$ & $3^{\prime}$-UTR \\
& & $\overline{100 \mathrm{bp}}$
\end{tabular}
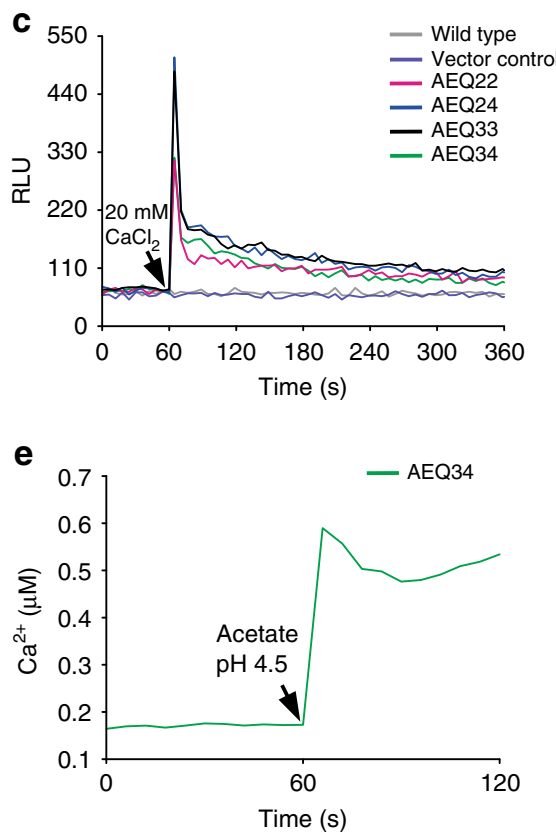

b
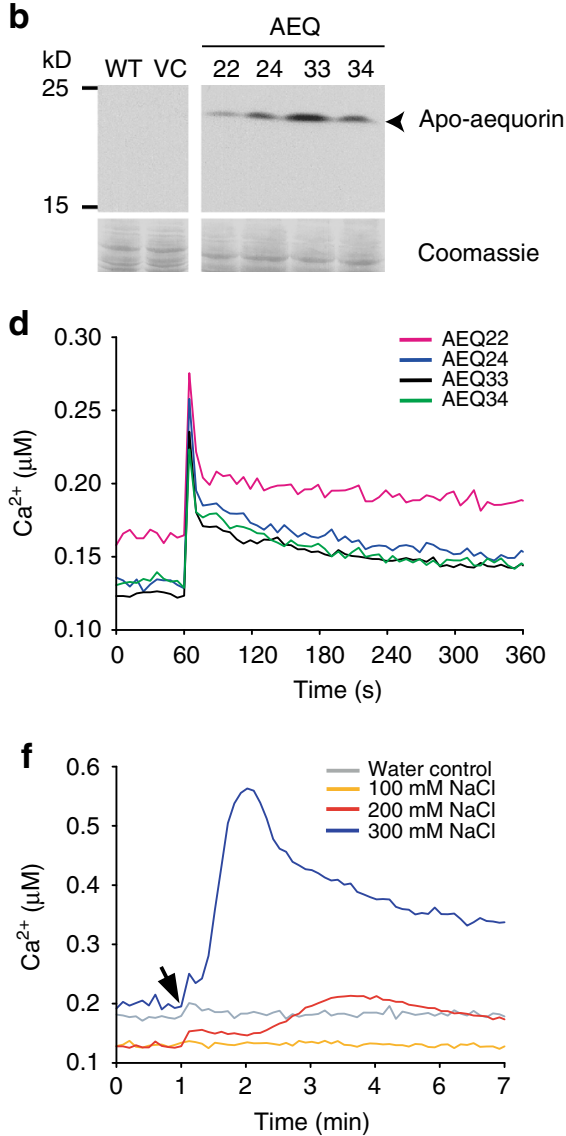

Fig. 3 Establishment of an aequorin-based calcium assay in C. reinhardtii and its applicability for abiotic stresses. a The apo-aequorin expression cassette includes a codon optimized gene and cis-acting elements for efficient expression (Supplementary Fig. 7). b Immunoblot showing the expression of apoaequorin (22 kD) in transgenic lines AEQ22, AEQ24, AEQ33, and AEQ34 compared to wild type (WT) and a vector control (VC). As a loading control, selected protein bands from the Coomassie-stained PVDF membrane are shown. Another biological replicate showed qualitatively identical results. c, $\mathbf{d}$ External calcium triggers luminescence in aequorin-expressing lines. After measuring the resting $\mathrm{Ca}^{2+}$ concentration in relative light units (RLU), $20 \mathrm{mM}$ of external $\mathrm{CaCl}_{2}$ were added as indicated by the black arrowhead. Obtained RLU values (c) were converted to relative $\mathrm{Ca}^{2+}$ concentrations (d) by triggering maximal luminescence (Supplementary Fig. 8). e Acidification of the medium causes a prompt increase in cytosolic $\mathrm{Ca}^{2+}$ ions. After measurement of the resting $\mathrm{Ca}^{2+}$ concentration, sodium acetate buffer $\mathrm{pH} 4.5$ was added to a final concentration of $20 \mathrm{mM}$ (black arrowhead) to AEQ34 cells in HEPES buffer $\mathrm{pH}$ 7.4. $\mathbf{f}$ Salt stress results in an increase in $\mathrm{Ca}^{2+}$ ions. Coelenterazine loaded cells of transgenic aequorin reporter line AEQ34 were treated with increasing concentrations of $\mathrm{NaCl}$ (black arrowhead) as indicated. As a control, an equivalent volume of deionized water was used. c-f Each line in the graphs represents the mean of three biological replicates and each biological replicate includes three technical replicates. All experiments were replicated twice except for $\mathbf{e}$, which was done once

5). Whereas no effect was observed for the negative control, upon the addition of orfamide $\mathrm{A}$, the cells stopped moving within 30-40 s. Light micrographs from orfamide A treated and untreated cells revealed that exposure to orfamide A results in the rapid deflagellation of algal cells (Fig. 2c). These results suggest that the bacteria employ orfamide $A$ as a tool to incapacitate the algal cells, and thus the algal cells lose the ability to evade the bacteria by swimming away.

The specificity of orfamide A-triggered loss of motility was further tested with flagellated algae other than C. reinhardtii. 
Therefore, a drop of algal cell suspension was placed in each case on a glass slide, and the cells were visualized using bright-field microscopy. A video was recorded before and after adding orfamide A. Negative controls with methanol that were carried out as well did not influence motility in any case (not shown). Other Chlorophyceae, such as the closely related marine
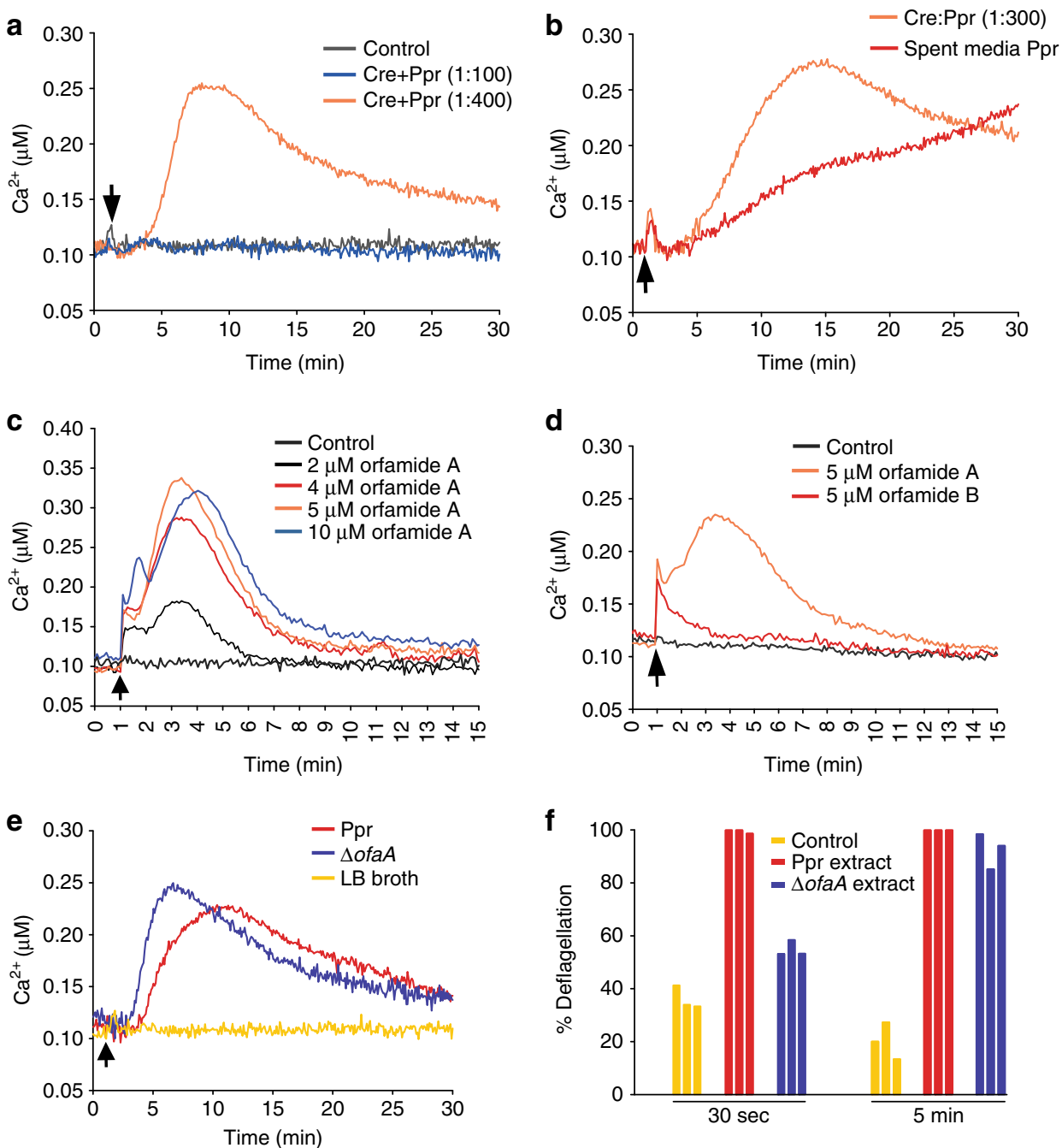

g
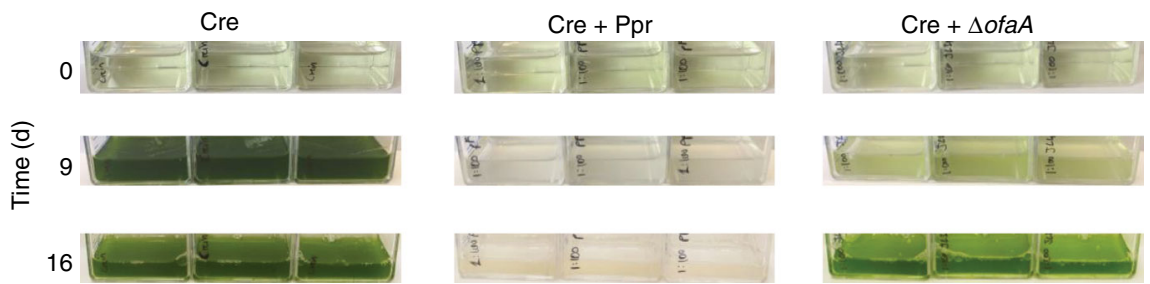

Fig. 4 Orfamides cause a rapid increase in cytosolic $\mathrm{Ca}^{2+}$ and contribute to deflagellation and algal growth arrest. a $P$. protegens is able to trigger Ca ${ }^{2+}$ changes in C. reinhardtii. Time course of cytosolic $\mathrm{Ca}^{2+}$ concentrations after addition of bacteria to AEQ34 cells. For the $\mathrm{Ca}^{2+}$ measurements, the bacterial cell density was adjusted to the indicated cell ratios. As control, LB broth was added (black arrowhead). $\mathbf{b}$ Effect of $P$. protegens spent medium on cytosolic $\mathrm{Ca}^{2+}$ levels in C. reinhardtii. Aequorin-expressing cells (AEQ34) were incubated with P. protegens in a ratio of 1:300 and used for the measurement. Further, sterile-filtered spent medium from an overnight culture of $P$. protegens (black arrowhead) was used. c Orfamide $\mathrm{A}_{\text {elicits }}$ dose-dependent $\mathrm{Ca}^{2+}$ changes. Orfamide A that was dissolved in methanol and further diluted in TAP medium was added to cells at the indicated concentrations. As control, methanol proportional to that of the highest concentration of orfamide A was used. d $\mathrm{Ca}^{2+}$ measurement upon treatment with $5 \mu \mathrm{M}$ orfamide $\mathrm{A}$ or $\mathrm{B}$. As control, methanol was used. e $\mathrm{Ca}^{2+}$ measurements with wild-type $P$. protegens or $\Delta$ ofaA mutant at a ratio of 1:400 of algae to bacteria. $\mathbf{f}$ Extracts prepared from supernatants of $P$. protegens and the $\triangle$ ofaA mutant cultures, respectively, having similar cell densities (around $3.14 \times 10^{8}$ and $3.16 \times 10^{8}$ cells $\mathrm{ml}^{-1}$, respectively) were incubated with $C$. reinhardtii at a $1 \%$ concentration for $30 \mathrm{~s}$ or $5 \mathrm{~min}$ in triplicates. A $1 \%$ extract of TAP medium was taken as control. $\mathbf{g}$ Liquid co-cultivation of $C$. reinhardtii together with wild-type $P$. protegens or $\Delta$ ofaA mutant compared to axenic algal cultures. A 1:100 ratio of algae to bacteria was used for inoculation with an initial concentration of $10^{5}$ algal cells per ml. The corresponding growth curves are depicted in Supplementary Fig. 12. a-e Each line in the graph represents the mean of three biological replicates, and each biological replicate includes three technical replicates. All experiments were replicated twice except for $\mathbf{f}$ that was performed once with one biological and three technical replicates. The experiment in $\mathbf{g}$ was performed twice with three biological replicates 
Chlamydomonas sp. SAG 25.89 (Supplementary Fig. 6), Haematococcus pluvialis of the order of Chlamydomonadales, as well as the colony-forming Gonium pectorale of the order of Volvocales lost motility to a large extent upon orfamide A treatment (Table 1; Supplementary Movies 6-11). In contrast, Pedinomonas minor, a Chlorophyte more distantly related to C. reinhardtii from the class of Pedinophyceae as well as the Euglenophyte, Euglena gracilis, retained motility upon orfamide A exposure (Table 1; Supplementary Movies 12-15). These data indicate that orfamide A specifically affects the motility of algae from the Chlorophyceae, whereas tested algae outside this taxonomic class are not vulnerable to this bacterial secondary metabolite.

Establishment of an aequorin reporter in C. reinhardtii. Since it is known that $\mathrm{Ca}^{2+}$ spikes can cause flagellar excision in $C$. reinhardtii ${ }^{26}$, we aimed at monitoring cytosolic $\mathrm{Ca}^{2+}$ changes in situ during the microbial interaction. For this purpose, we established an aequorin reporter system in C. reinhardtii. We constructed a gene cassette containing the apo-aequorin gene of Aequoria victoria ${ }^{27}$, which was codon optimized for efficient expression in C. reinhardtii, and introduced it into the algal cells (Fig. 3a and Supplementary Fig. 7). Several transgenic lines (AEQ22, AEQ24, AEQ33, and AEQ34) expressed the 22-kD apoaequorin successfully (Fig. $3 \mathrm{~b}$ ) and were selected for further examination.

As high extracellular $\mathrm{Ca}^{2+}$ concentrations reportedly cause an increase of cytosolic $\mathrm{Ca}^{2+}$ levels ${ }^{28}$, we initially analyzed aequorin activities by providing external $\mathrm{Ca}^{2+}$ to the AEQ cell lines. Notably, upon addition of excess of external $\mathrm{Ca}^{2+}$, all four transgenic AEQ lines immediately showed a luminescence spike (Fig. 3c). This response was neither observed in the wild type nor in the negative control containing the vector only. In order to estimate the intracellular $\mathrm{Ca}^{2+}$ concentrations, cell lysis was performed at the end of the measurement using an ethanolcontaining saturating solution of $\mathrm{Ca}^{2+}$ to trigger the maximum luminescence (Supplementary Fig. 8; Fig. 3d). We also compared maximum luminescence values dependendent on the age of the cells, which was the highest during the exponential growth phase (Supplementary Fig. 9). To further validate our reporter system, abiotic stimuli (abrupt acidification ${ }^{29}$ and salt stress ${ }^{30}$ ) previously demonstrated to increase intracellular $\mathrm{Ca}^{2+}$ levels were applied to the transgenic strains. In both cases, the luminescence increased as expected (Fig. 3e, f).

Orfamides trigger a $\mathrm{Ca}^{2+}$ signal and influence algal growth. With a reliable aequorin reporter system at hand, we next studied the biotic interactions of $C$. reinhardtii. The $\mathrm{Ca}^{2+}$ response in aequorin-expressing $C$. reinhardtii cells was measured in the presence of $P$. protegens cells at different ratios (algae:bacteria $1: 100$ and $1: 400)$. At a $1: 100$ ratio, no changes in cytosolic $\mathrm{Ca}^{2+}$ levels could be observed within the first $30 \mathrm{~min}$ of incubation (Fig. 4a), whereas a strong $\mathrm{Ca}^{2+}$ signal occurred at a ratio of 1:400 after just $5 \mathrm{~min}$. These results show that the interaction between C. reinhardtii and $P$. protegens cells results in a very fast alteration of the intracellular $\mathrm{Ca}^{2+}$ level, once a critical number of bacterial cells surrounding the algae (Supplementary Movie 1) is reached. In contrast, when adding $X$. campestris or $F$. johnsoniae cells at the same ratios, no $\mathrm{Ca}^{2+}$ release was triggered (Supplementary Fig. 10a and b). Even a 4500-fold excess of X. campestris or F. johnsoniae did not trigger a $\mathrm{Ca}^{2+}$ signal, demonstrating that the response of $C$. reinhardtii is not generally caused by the presence of bacteria, but it is specific to P. protegens.

We also found that a direct contact of $P$. protegens with the algal cells is not required to trigger the $\mathrm{Ca}^{2+}$ release. The cell-free supernatant of the bacterial culture also caused a signal in the aequorin reporter line (Fig. 4b), thus showing that a diffusible signal is responsible for the $\mathrm{Ca}^{2+}$ release. Next, we tested the capability of orfamide A to cause alterations in cytosolic $\mathrm{Ca}^{2+}$ in a manner similar to the coculture and the supernatant of $P$. protegens. Solutions of pure orfamide A at different concentrations were added to the algal aequorin reporter line. Whereas the control with the solvent alone showed no alteration, we observed a dose-dependent change in the $\mathrm{Ca}^{2+}$ levels up to $\sim 5 \mu \mathrm{M}$ orfamide A within the first $5 \mathrm{~min}$ after the addition of orfamide A. Higher levels of orfamide A $(10 \mu \mathrm{M})$ resulted in saturation (Fig. $4 \mathrm{c}$ ). These data unequivocally show that orfamide A affects $\mathrm{Ca}^{2+}$ homeostasis in the bacterial-microalgal interaction. In addition, the concentration-dependent response up to ca. $5 \mu \mathrm{M}$ orfamide $\mathrm{A}$ mirrors the effect of the bacterial cell density when surrounding the algae, thus causing a high orfamide A concentration in the vicinity of the microalgae.

The extended response of C. reinhardtii to the spent media of $P$. protegens (Fig. $4 \mathrm{~b}$ ) suggested that chemical mediators other than orfamide A may also contribute to the signal. As orfamide B was also identified in P. protegens (Supplementary Fig. 5) and is commercially available, we analyzed if it has a similar effect as orfamide $\mathrm{A}$. We observed that orfamide $\mathrm{B}$ triggers a $\mathrm{Ca}^{2+}$ release, whose signature, however, differs from that of orfamide A (Fig. 4d). A sharp peak of low amplitude observed immediately after the addition of orfamide $\mathrm{A}$ was also present with orfamide $\mathrm{B}$, but the larger and broader response found with orfamide A was missing. Yet, orfamide B deflagellates the algal cells (Supplementary Fig. 11).

Orfamides are biosynthesized from an operon consisting of three structural genes known as $o f a A$, of $a B$, and of $a C$, encoding nonribosomal peptide synthetases ${ }^{31,32}$. To investigate the in vivo role of orfamides in algal-bacterial mixed cultures, we used a $\Delta o f a A$ mutant $^{25}$ that lacks all orfamides. The observation that this mutant is still able to elicit a $\mathrm{Ca}^{2+}$ signal (Fig. 4e) indicates that $P$. protegens produces infochemicals other than the orfamides with the capacity to influence the cytosolic $\mathrm{Ca}^{2+}$ levels in $C$. reinhardtii. However, a $1 \%$ extract from the culture supernatant of the $\Delta o f a A$ mutant deflagellated algal cells after 30 s only at a relatively low rate compared to the supernatant from a $P$. protegens culture (Fig. $4 \mathrm{f}$ ). After a longer incubation time (5 min), the rate of deflagellation was high in both cases (Fig. 4f). These data show that the orfamides contribute to the rapid deflagellation event of algal cells. We also looked at the growth of algal cells in coculture with the mutant. Although the $\Delta o f a A$ mutant initially suppressed algal growth in a coculture assay, the algae recovered and started to grow after 9-10 days (Fig. 4g; Supplementary Fig. 12). In contrast, wild-type $P$. protegens suppressed algal growth over a period of 19 days. Although these data provide strong evidence that further secondary metabolites contribute to the complex interplay between $P$. protegens and the algae, they clearly suggest at the same time that the orfamides are involved in the antagonistic effect exerted by $P$. protegens on the algae.

Orfamide induces channel-based influx of extracellular $\mathrm{Ca}^{2+}$. In the next step, we focused further on the effect of orfamide A and examined if it is able to alter the morphology of C. reinhardtii, as observed after 24 -h incubation of the algae with $P$. protegens (Fig. 1d). Exposure of algal cells to $35 \mu \mathrm{M}$ orfamide A resulted in deflagellation, as described before, but the oval shape of the cells was largely unaffected (Fig. 5a, left image). In a few cases, a circular and enlarged morphology was also visible after $24 \mathrm{~h}$ (Fig. 5a, medium and right images) that was not observed in the control. These data show that orfamide A has the capability to alter the morphology and suggest that a coordinated action of 
orfamides as well as of other chemical compounds is needed for large-scale changes in morphology after $24 \mathrm{~h}$.

We further checked if the deflagellation and the increase in $\mathrm{Ca}^{2+}$ in the algal cells are caused by permeabilization effects by orfamide A using the vital stain Evans blue. In the positive control, $10 \mu \mathrm{M}$ mastoparan, known as a permeabilization agent ${ }^{33}$, leads to an efficient staining of approximately $80 \%$ of the Chlamydomonas cells with Evans blue (Fig. 5b) and concomitant high rates of deflagellation (Fig. 5c). In contrast, $35 \mu \mathrm{M}$ (used in Fig. 2c) as well as $10 \mu \mathrm{M}$ orfamide A, which still causes $\sim 80 \%$ of deflagellation (Fig. 5c) did not result in an increased staining of Chlamydomonas cells compared to the control (Fig. 5b). Algal cells treated with $10 \mu \mathrm{M}$ orfamide B did not show increased permeability to Evans blue either (Supplementary Fig. 11). These data show that orfamides do not provoke a major permeabilization of the algal cells - at least not on a short term-for orfamideinduced deflagellation in Chlorophyceae as observed with orfamide A (Table 1, see Discussion).

To investigate whether the orfamide-mediated rise in cytosolic $\mathrm{Ca}^{2+}$ is due to an influx of $\mathrm{Ca}^{2+}$ from the extracellular medium or if it is released from intracellular $\mathrm{Ca}^{2+}$ stores, we resuspended the cells in a medium lacking $\mathrm{Ca}^{2+}$ ions that had been additionally supplemented with $50 \mu \mathrm{M}$ EGTA to sequester any possibly existing residual $\mathrm{Ca}^{2+}$ ions. Upon exposure of the cells to orfamide $\mathrm{A}$, we observed only a very small increase in $\mathrm{Ca}^{2+}$ in this case, indicating that the orfamide-triggered rise in $\mathrm{Ca}^{2+}$ requires an influx of $\mathrm{Ca}^{2+}$ from outside the cell (Fig. 5d). We also investigated the link between the presence of $\mathrm{Ca}^{2+}$ in the medium,

a
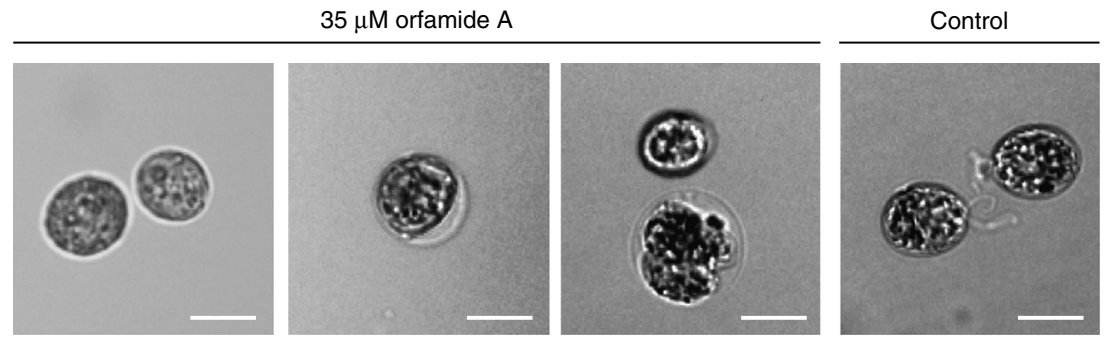

b

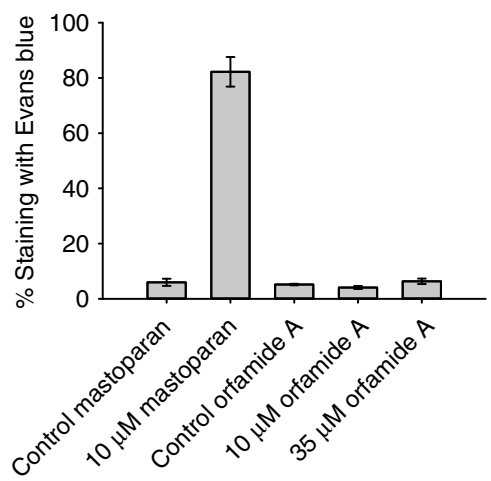

d

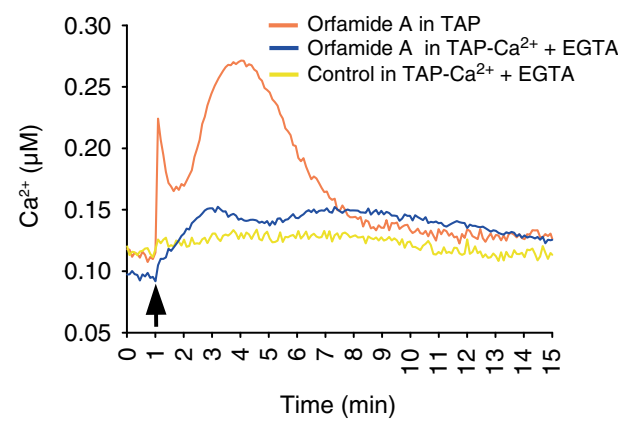

f

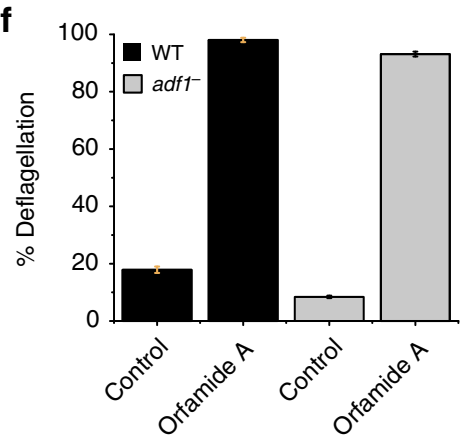

C
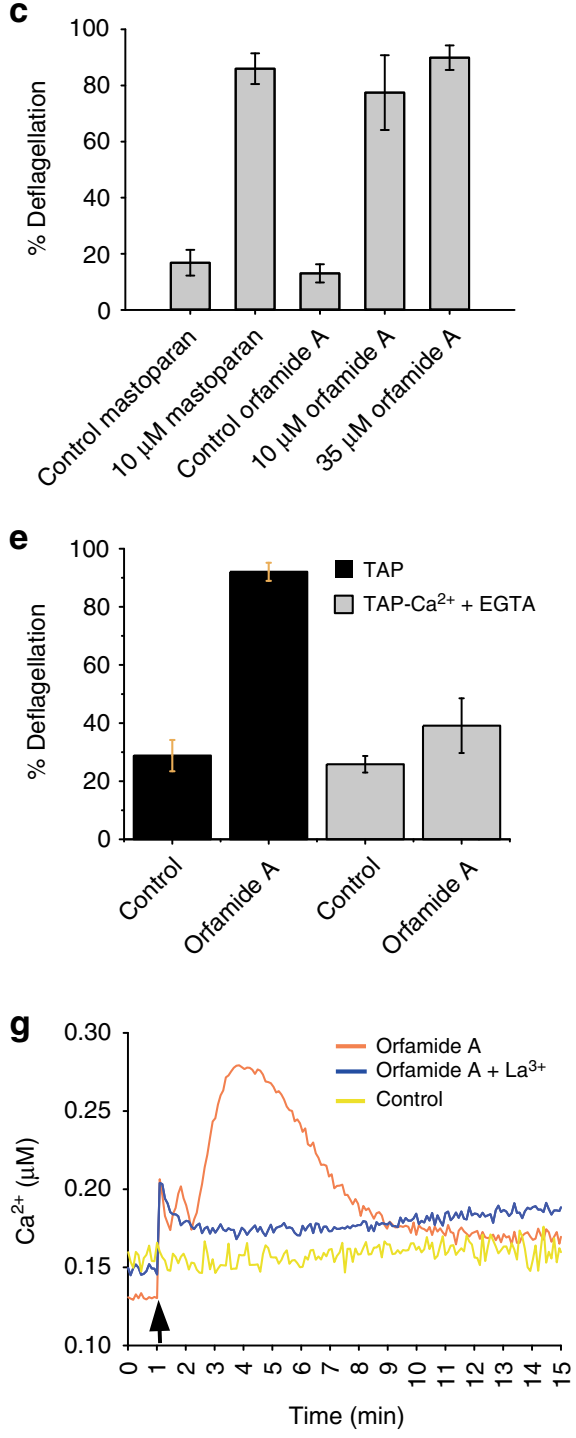
the action of orfamide A, and deflagellation. For this purpose, we examined the rate of orfamide-induced deflagellation in $C$. reinhardtii in a medium with or without $\mathrm{Ca}^{2+}$. Clearly, orfamide A-based deflagellation depends on the presence of $\mathrm{Ca}^{2+}$ in the medium (Fig. 5e). These findings link the $\mathrm{Ca}^{2+}$ uptake caused by the presence of orfamide $\mathrm{A}$ and consequently triggered deflagellation, pointing to the cytosolic $\mathrm{Ca}^{2+}$ elevation as the trigger for deflagellation.

In the next step, we used a mutant known as adf-1, which encodes for a $\mathrm{Ca}^{2+}$ channel shown to be responsible for deflagellation via influx of $\mathrm{Ca}^{2+}$ upon acid shock. The involved $\mathrm{Ca}^{2+}$ channel was recently identified as TRP15 29,34 . The adf-1 mutant was efficiently deflagellated upon orfamide A treatment (Fig. 5f), suggesting that the TRP15 channel is not involved (or is at least not the only $\mathrm{Ca}^{2+}$ channel) in the orfamide A signaling pathway. If the $\mathrm{Ca}^{2+}$ channel blocked in the adf-1 mutant was the sole channel mediating the $\mathrm{Ca}^{2+}$ influx, orfamide A would not cause a significant increase in $\mathrm{Ca}^{2+}$ in this mutant and the mutant would not deflagellate. In contrast, if another $\mathrm{Ca}^{2+}$ channel of Chlamydomonas is involved, deflagellation would occur.

To test this possibility, we used lanthanum $\left(\mathrm{La}^{3+}\right)$, a wellknown inhibitor of $\mathrm{Ca}^{2+}$ channels ${ }^{29,35}$. The addition of orfamide $\mathrm{A}$ in the presence of $\mathrm{La}^{3+}$ resulted in a massively reduced level of $\mathrm{Ca}^{2+}$ compared to the absence of $\mathrm{La}^{3+}$ (Fig. 5g). Altogether, our results indicate that orfamide $\mathrm{A}$ from $P$. protegens induces the influx of extracellular $\mathrm{Ca}^{2+}$ through an unidentified $\mathrm{Ca}^{2+}$ channel (other than TRP15) in the algal plasma membrane.

\section{Discussion}

$\mathrm{Ca}^{2+}$ signaling has been implicated in early stages of higher plant-microbe interactions of both symbiotic and antagonistic nature ${ }^{36}$. Likewise, in marine diatoms, environmental signals and intraspecies interactions can activate $\mathrm{Ca}^{2+}$ signaling 33,38 . By means of an aequorin reporter line, we have demonstrated that bacteria substantially perturb the cytosolic $\mathrm{Ca}^{2+}$ levels in $C$. reinhardtii at different time scales, within minutes (Fig. 4a) to hours (Supplementary Fig. 13). The changes in $\mathrm{Ca}^{2+}$ do not necessarily result in deflagellation of a $C$. reinhardtii cell, but are also involved in light-signaling pathways from the eyespot to the flagella, thus controlling algal movements ${ }^{39}$. Similarly, elevated salt concentrations evoke an increase in $\mathrm{Ca}^{2+}$, but not deflagellation ${ }^{30}$. The strong rise in $\mathrm{Ca}^{2+}$ in response to acidification and salt stress $26,29,30$ was confirmed with the aequorin assay in this study (Fig. 3e, f), and a rapid increase in $\mathrm{Ca}^{2+}$ is also evident upon orfamide A and B treatment (Fig. 4d).

Experiments with calcium-sensitive dyes have shown that localization of $\mathrm{Ca}^{2+}$ primarily in the apical part of the algal cell and the timing of the $\mathrm{Ca}^{2+}$ signals are important factors in acid- induced deflagellation ${ }^{26}$. In agreement with this regulatory role of $\mathrm{Ca}^{2+}$ signals in deflagellation, we observed that both orfamideinduced $\mathrm{Ca}^{2+}$ elevation (Fig. 5d) and deflagellation (Fig. 5e) depend on the presence of extracellular $\mathrm{Ca}^{2+}$ ions. Although stresses often elicit $\mathrm{Ca}^{2+}$ responses in $C$. reinhardtii that can lead to deflagellation 29,30 , our results point to a more specific role of orfamides. We show that orfamide A exposure results in cytosolic $\mathrm{Ca}^{2+}$ increase, which requires a $\mathrm{Ca}^{2+}$ influx from outside the cell without causing a major permeabilization of the plasma membrane (Figs. $4 \mathrm{c}$ and $5 \mathrm{~b}, \mathrm{~d}$ ). The fact that this $\mathrm{Ca}^{2+}$ signal is inhibited by $\mathrm{La}^{3+}$ (Fig. 5g), a Ca ${ }^{2+}$ channel blocker ${ }^{29}, 35$, suggests that orfamide $\mathrm{A}$ targets a $\mathrm{Ca}^{2+}$ channel in the algal plasma membrane. In the light of these findings, an alternative mode of action of orfamides as $\mathrm{Ca}^{2+}$ carriers or small $\mathrm{Ca}^{2+}$-selective pores that are not permeable to Evans blue seems to be less likely, but remains to be tested.

In this context, it is also of interest that Chlamydomonas has an unusually high number ( $>30$ predicted by its genome) of $\mathrm{Ca}^{2+}$ channels, especially of the TRP type ${ }^{40}$, most of which have not been characterized so far. It seems likely that one of them is part of the orfamide-signaling pathway. Since the well-characterized Chlamydomonas TRP15 $\mathrm{Ca}^{2+}$ channel $^{34}$ is not involved in orfamide A-triggered $\mathrm{Ca}^{2+}$ uptake (or is not the only $\mathrm{Ca}^{2+}$ channel involved in this process) (Fig. 5f), the target of orfamide remains to be identified. Orfamide A may bind directly to its $\mathrm{Ca}^{2+}$ channel target, or induce channel opening indirectly, for example, by binding to another protein or lipid component of the plasma membrane. The distinct response of orfamide B (Fig. 4d) that differs from orfamide A by only one methyl group (Fig. 2b) might indicate that orfamide $\mathrm{B}$ may even trigger a different pathway than orfamide A. The specificity of orfamide A in immobilizing Chlorophyceae algae, but not two species from the Pedinophyceae and Euglenophytes, respectively (Table 1), further supports a specific mechanism and a signaling role of these cyclic lipopeptides that involves specialized membrane components unique to Chlorophyceae.

The majority of characterized lipopeptides interacts with lipid components of membranes, such a daptomycin, which was recently found to interfere with fluid membrane microdomains ${ }^{41}$. In some cases, however, protein targets were also identified ${ }^{42}$. In addition to the deflagellating and $\mathrm{Ca}^{2+}$-eliciting activities associated with orfamide $\mathrm{A}$, which manifest themselves within minutes (Figs. $2 \mathrm{c}$ and $4 \mathrm{c}$ ), this secondary metabolite also starts to disturb the morphology of $C$. reinhardtii over a time scale of $24 \mathrm{~h}$ (Fig. 5a). While staining with Evans blue indicates that orfamide A does not disrupt the algal cell membrane on the short term (Fig. 5b), membrane disruption may occur on the long term. Whether the different effects of orfamide A on C. reinhardtii are

Fig. 5 Orfamide $A$ induces influx of extracellular $\mathrm{Ca}^{2+}$, probably through an unidentified channel. a Cell morphology of $\mathrm{C}$. reinhardtii exposed to $35 \mu \mathrm{M}$ of orfamide $A$ after $24 \mathrm{~h}$. The density of algal cells was $4 \times 10^{6}$ cells ml $^{-1}$. Algal cells were observed by bright-field microscopy using a magnification of $\times 400$ (scale bar: $10 \mu \mathrm{m}$ ). b Evans blue staining of wild-type C. reinhardtii (strain SAG 73.72) upon treatment with orfamide A and mastoparan at the indicated concentrations. As controls, methanol or water were used at equivalent concentrations. c Deflagellation of wild-type $C$. reinhardtii upon treatment with orfamide A and mastoparan at the indicated concentrations. As control, methanol or water were used at equivalent concentrations. $\mathbf{d}$ Orfamide A triggers $\mathrm{Ca}^{2+}$ changes mostly from external pools. AEQ34 cells were grown in TAP medium for $72 \mathrm{~h}$. Before incubation with coelenterazine, the TAP medium was replaced with TAP lacking $\mathrm{Ca}^{2+}$ and the cells were incubated with $50 \mu \mathrm{M}$ EGTA for 5 minutes before commencing the $\mathrm{Ca}^{2+}$ measurement. As negative control, AEQ34 cells in TAP lacking $\mathrm{Ca}^{2+}$ were treated with methanol. e Deflagellation of wild-type $\mathrm{C}$. reinhardtii upon treatment with $35 \mu \mathrm{M}$ of orfamide $\mathrm{A}$ in TAP medium or TAP lacking $\mathrm{Ca}^{2+}$ (see $\mathbf{d}$ ). In the latter case, the cells were washed three times with TAP lacking Ca ${ }^{2+}$ supplemented with $50 \mu \mathrm{M}$ EGTA before the treatment with orfamide A. f Deflagellation in the adf- 1 mutant and its underlying wild type (WT, strain CC-620) upon treatment of cells with 35 $\mu \mathrm{M}$ of orfamide A. $\mathbf{g}$ Lanthanum ( $\mathrm{La}^{3+}$ ) inhibits orfamide-induced $\mathrm{Ca}^{2+}$ signaling. Overall, $20 \mu \mathrm{M} \mathrm{LaCl}$ were added to the cells in HEPES buffer, pH 7.4, 1 min before the $\mathrm{Ca}^{2+}$ measurement was started. In $\mathbf{b}, \mathbf{c}, \mathbf{e}$, and $\mathbf{f}$, all experiments were performed with three biological replicates and were replicated twice $(\mathbf{b}, \mathbf{c}, \mathbf{f})$ or once $(\mathbf{e})$. Error bars represent the standard deviation. In $\mathbf{d}$ and $\mathbf{g}$, each line in the graph represents the mean of three biological replicates, and each biological replicate includes three technical replicates. Except for $\mathbf{a}$, which was performed once, all experiments were replicated twice. In $\mathbf{a}$, representative pictures are shown 


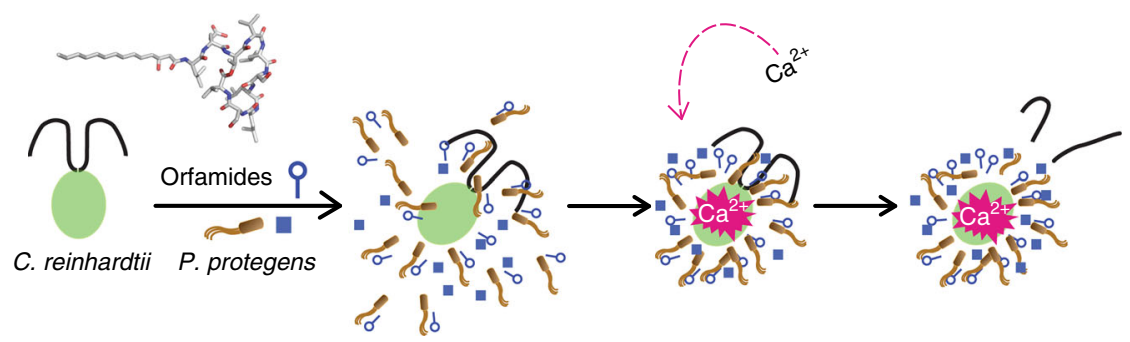

Fig. 6 Proposed model of paralysis of algal cells by $P$. protegens. During the antagonistic interaction of $P$. protegens with $C$. reinhardtii, the cyclic lipopeptide orfamide $A$ as well as yet unknown other chemical mediator(s) (indicated by blue squares) produced by the bacteria accumulate around the algal cells. Orfamides and the other compound(s) elicit a cytosolic $\mathrm{Ca}^{2+}$ signal in the green algae by triggering the influx of external $\mathrm{Ca}^{2+}$, at least in the case of orfamide A. Algal cells then become paralyzed by deflagellation, which seems to help P. protegens to acquire micronutrients

based on a single or multiple molecular interactions with components of the algal plasma membrane needs to be addressed in future work. In zoospores of the oomycete Phytophthora ramorum, a nonphotosynthetic member of the Heterokontophyta, orfamide A causes both immobilization and cell lysis within minutes ${ }^{31}$. The structure of the cell wall, which is absent from $P$. ramorum zoospores, and also the composition of the plasma membrane may explain why orfamide A exerts different effects on $P$. ramorum ${ }^{31}$ and different photosynthetic algae (Table 1; Figs. 1d and 2c).

Mutation of ofa $A$ in $P$. protegens results in the stop of orfamide production and defects in swarming (movement on soft agar) of the bacteria ${ }^{31}$. Bacterial lipopeptides, specifically orfamides, have been known to play different roles, e.g., as biosurfactants, as antifungal biocontrol agents, or as insecticides ${ }^{31,43}$. We have now revealed an interkingdom function of orfamides $A$ and $B$ as precise saboteurs of eukaryotic signaling pathways, resulting in the immobilization of flagellated algal cells by interference with intracellular $\mathrm{Ca}^{2+}$ homeostasis. These cyclic lipopeptides thus represent novel biotic factors that cause $\mathrm{Ca}^{2+}$-dependent deflagellation in microalgae. Experiments with the $\Delta o f a A$ mutant (Fig. 4e, f, g) showed that orfamides are not essential for $P$. protegens to induce $\mathrm{Ca}^{2+}$ signaling and deflagellation in C. reinhardtii. The algal $\mathrm{Ca}^{2+}$ signal elicited by the $\Delta o f a A$ mutant was slightly faster than the signal elicited by the wild type (Fig. 4e), whereas deflagellation was delayed when an extract from the $\triangle o f a A$ mutant was used (Fig. 4f). Although the reason for these different effects is currently unclear, not every $\mathrm{Ca}^{2+}$ signal triggers deflagellation (as mentioned above), and different $\mathrm{Ca}^{2+}$ signatures may induce different downstream responses with different efficiencies. Our findings with the $\Delta o f a A$ mutant further show that $P$. protegens also produces other chemical mediators in addition to orfamides that possess $\mathrm{Ca}^{2+}$-eliciting and deflagellating activities, albeit rapid deflagellation (within $30 \mathrm{~s}$ ) seems to be mainly associated with exposure to orfamides (Fig. 4f). Although these mediators may employ the same or alternative signaling pathways compared to orfamide $\mathrm{A}$, the observed redundancy may indicate that $\mathrm{Ca}^{2+}$ elicitors and deflagellating compounds could aid to improve the fitness of $P$. protegens. In any case, the recovery of algal growth in the presence of the $\Delta o f a A$ mutant after $\sim 10$ days (Fig. 4g) indicates that a few algae survive the encounter when orfamides are absent, highlighting that orfamides help P. protegens to compete with $C$. reinhardtii.

The strategy used by $P$. protegens (Fig. 6) differs markedly from previously reported tactics of bacteria that secrete algicidal agents and results in high concentrations of orfamides around the algal cells simply by the accumulation of the bacteria around the algae, as visualized in Supplementary Movie 1. This behavior results in the stop of the algal growth and altered cell morphology (Fig. 1b, d). We hypothesize that immobilization of the algal cells helps the bacteria to acquire nutrients from the algae. Bacterial growth is enhanced in coculture when the surrounding medium lacks trace elements (Supplementary Fig. 2), which are most likely delivered by the algal cells. However, the evidence for a benefit for the bacteria is currently limited, and further experiments are necessary to identify the specific nutrients obtained from the compromised algal cells. In addition to one or more trace elements, phosphate or sources of carbon or nitrogen that are present in the used medium may also have a role in the algal-bacterial interplay.

Beyond the new molecular insights, our findings also seem to be relevant from an ecological perspective because they contribute to a better mechanistic understanding of algal blooms that are part of phytoplankton. Algal blooms can affect the environment in two ways; they are not only major contributors to global photosynthesis, but can also be highly toxic, poisoning fish and shellfish ${ }^{44}$. Unicellular flagellated algae and colony-forming algae such as Gonium or Pleodorina, which are related to C. reinhardtii, can also form blooms ${ }^{45}$. Our data show that closely related wet soil and freshwater, as well as marine Chlorophyceae are likely subject to a similar deflagellation mechanism as C. reinhardtii because they get immobilized by orfamide A (Table 1). P. protegens is found in all these environments ${ }^{17,46}$, and $P$. protegens and a closely related $P$. fluorescens strain have been reported to control algal blooms in freshwater and marine ecosystems, respectively 3,44 . Therefore, the microbial interaction that we unraveled seems to be transferable to other flagellate Chlorophyceae algae, thus providing new tools to interfere with algal blooms of such species.

\section{Methods}

Strains and culture conditions. C. reinhardtii strain SAG $73.72\left(\mathrm{mt}^{+}\right)$was used as a wild type for most of the performed experiments. In some cases, mutant adf-1 (CC-2919) with a defect TRP15 $\mathrm{Ca}^{2+}$ channel was used together with its parental strain CC-620. SAG 73.72 was obtained from the algal culture collection in Göttingen and CC-620, as well as the mutant CC-2919 from the Chlamydomonas Center at the University of Minnesota, USA. C. reinhardtii cells were grown in Tris-acetate-phosphate (TAP) medium ${ }^{47}$ in a light dark regime of 12:12 (unless otherwise indicated) with a light intensity of $50 \mu \mathrm{mol}$ photons $\mathrm{m}^{-2} \mathrm{~s}^{-1}$ and stirring $(250 \mathrm{rpm})$. The bacterial strains $F$. johnsoniae UW101 ${ }^{48}, X$. campestris pv. campestris ATCC $33913^{49}$, and $P$. fluorescens $\mathrm{Pf}-5^{50}$ renamed to $P$. protegens $\mathrm{Pf}-5^{17}$ were usually grown in LB medium at $28^{\circ} \mathrm{C}$ with orbital shaking $(200 \mathrm{rpm})$. The $\Delta o f a A$ deletion mutant ${ }^{25}$ was kindly provided by H. Gross (University of Tübingen), which he had obtained in turn from J.E. Loper (Oregon State University, USA) and B.T. Shaffer (OSU and UCSD-ARS). For the agar-based coculture assay, algal cells were grown under continuous light conditions $\left(50 \mu \mathrm{mol}\right.$ photons $\mathrm{m}^{-2} \mathrm{~s}$ ${ }^{-1}$ ). Bacterial cells were grown in TAP medium for this coculture assay. Transgenic cell lines expressing the apo-aequorin reporter (AEQ, see below) were maintained on TAP agar plates $\left(2 \%\right.$ agar) with hygromycin $\mathrm{B}\left(20 \mu \mathrm{g} \mathrm{ml}^{-1}\right)$. For $\mathrm{Ca}^{2+}$ measurement experiments, algal cells were grown in TAP medium without any antibiotics and the bacteria were grown in LB medium.

Other flagellate algae were obtained from the culture collection of algae and protozoa of the Scottish Marine Institute in United Kingdom (Haematococcus pluvialis, strain CCAP 34/8 and Gonium pectorale, strain CCAP 32/4), from the culture collection in Göttingen, Germany (Chlamydomonas sp., strain SAG 25.89 that was identified as CCMP 235, see Supplementary Fig. 6 and Euglena gracilis, strain SAG 1224-5/25) or were kindly provided by C. Wilhelm (Pedinomonas minor, SAG 1965-3), University of Leipzig, Germany. These flagellate algae were 
grown in media whose recipes are provided by the mentioned algal collections. Briefly, H. pluvialis, G. pectorale, and P. minor were grown in $3 \mathrm{~N}-\mathrm{BBM}+\mathrm{V}$ medium, E. gracilis in $3 \mathrm{~N}-\mathrm{BBM}+\mathrm{V}$ supplemented with $1 \mathrm{gl}^{-1}$ sodium acetate trihydrate, $1 \mathrm{gl}^{-1}$ meat extract, $2 \mathrm{gl}^{-1}$ tryptone, and $2 \mathrm{gl}^{-1}$ yeast extract, and Chlamydomonas sp. SAG 25.89 in a modified version of $3 \mathrm{~N}-\mathrm{BBM}+\mathrm{V}$ where $32 \mathrm{gl}^{-1}$ $\mathrm{NaCl}$ had been added and the $\mathrm{NaNO}_{3}$ had been replaced with $7 \mathrm{mM} \mathrm{NH} \mathrm{NH}_{4} \mathrm{Cl}$.

Co-cultivation of $\boldsymbol{C}$. reinhardtii and bacteria. For mixed cultivation of algae and bacteria on agar plates, a TAP plate ( $2 \%$ agar, $92 \mathrm{~mm}$ diameter) was overlaid with $3.3 \mathrm{ml} 0.5 \%$ TAP agar (cover agar) containing $2 \times 10^{6}$ C. reinhardtii cells. Overall, $15 \mu \mathrm{l}$ of an overnight bacterial culture (containing between 2.1 and $2.5 \times 10^{6}$ cells) were then applied to the surface of the solidified plate. The plates were incubated under continuous light $\left(50 \mu \mathrm{mol}\right.$ photons $\left.\mathrm{m}^{-2} \mathrm{~s}^{-1}\right)$ at $20^{\circ} \mathrm{C}$ and documented by scanning. For the mixed cultivation of algae and bacteria in liquid culture, $C$. reinhardtii and bacteria were grown in $100 \mathrm{ml}$ conical flasks containing $50 \mathrm{ml}$ TAP medium under continuous light $\left(50 \mu \mathrm{mol}\right.$ photons $\left.\mathrm{m}^{-2} \mathrm{~s}^{-1}\right)$ and stirring $(200 \mathrm{rpm})$ at $20^{\circ} \mathrm{C}$. Algal cell densities were determined by counting using an improved Neubauer chamber (no. T729.1, Carl Roth, Karlsruhe, Germany). Bacterial cell densities were determined as colony-forming units (CFU) by plating diluted bacterial culture on LB agar plates and counting CFUs.

For recording the cell densities of algae (C. reinhardtii) alone and in coculture with bacteria (P. protegens or the $\triangle o f a A$ mutant) (Supplementary Fig. 12), cells were grown in $50 \mathrm{ml}$ NUNC cell culturing flasks containing $20 \mathrm{ml}$ of TAP medium on a rotary shaker $(200 \mathrm{rpm})$ at $23^{\circ} \mathrm{C}$. For each time-point, $1 \mathrm{ml}$ of culture was transferred into a $2 \mathrm{ml}$ Eppendorf tube, cooled down to $4^{\circ} \mathrm{C}$ and centrifuged for $2.5 \mathrm{~min}$ at $200 \times \mathrm{g}$. The supernatant containing the bacteria was transferred to a new Eppendorf tube and the pellet bearing the algal cells was resuspended in $1 \mathrm{ml}$ of TAP medium. OD was then measured at $700 \mathrm{~nm}$ and the cell density was estimated using a calibration curve done with the axenic cultures of $C$. reinhardtii.

For mixed cultivation of $C$. reinhardtii and P. protegens in liquid TAP medium free of trace elements (TAP-TE), bacteria were washed three times in TAP-TE medium and used to inoculate $50 \mathrm{ml}$ TAP-TE in $100 \mathrm{ml}$ conical flasks to an initial density of $10^{6}$ cells $\mathrm{ml}^{-1}$. Bacteria were grown under continuous light $(50 \mu \mathrm{mol}$ photons $\mathrm{m}^{-2} \mathrm{~s}^{-1}$ ) and stirring $(200 \mathrm{rpm})$ at $20^{\circ} \mathrm{C}$. After $24 \mathrm{~h}$, algae were added at a ratio of 1:100 algae to bacteria, and the growth of the bacteria was determined by plating different dilutions on LB agar plates and counting CFUs.

To record Supplementary Movie 1, wild-type cells of C. reinhardtii were grown to a cell density of $3-4 \times 10^{6} \mathrm{cells} \mathrm{ml}^{-1}$. $20 \mu \mathrm{l}$ of algal cells in TAP medium were dripped on a glass slide and a coverslip was placed gently over the spot. A total of $10 \mu \mathrm{l}$ of a bacterial culture grown overnight (in LB medium) were introduced from the corner of the coverslip. The cells were observed under the microscope at $\times 400$ magnification using the software Zen (blue edition, Carl Zeiss).

To record Supplementary Movies 2-15 (documentation of the effect of orfamide A on the motility of C. reinhardtii and other flagellate algae), $18 \mu$ of algal culture $\left(3 \times 10^{6} \mathrm{ml}^{-1}\right)$ were placed as drop on an 8 well diagnostic glass slide (Thermo scientific) except for E. gracilis, where a concentration of $6 \times 10^{5} \mathrm{ml}^{-1}$ cells was used due to its large cell size. Overall, $2 \mu \mathrm{l}$ of orfamide A in the corresponding medium were carefully added to the droplet to reach a final concentration of $35 \mu \mathrm{M}$ orfamide A. The cells were visualized and recorded in movie using the software Zen (Blue edition, Carl Zeiss) before and after 30-60 s adding orfamide A. In case of P. minor and E. gracilis, movies were taken after 5 min to verify that orfamide A still has no effect after a longer period. All experiments for the Supplementary Movies were replicated twice.

Acridine orange staining and fluorescence microscopy. C. reinhardti $\left(4 \times 10^{6}\right.$ cells ml $\left.{ }^{-1}\right)$ and $P$. protegens $\left(1.7 \times 10^{9} \mathrm{CFU} \mathrm{ml}^{-1}\right)$ cells were mixed in a ratio of algae to bacteria of $\sim 1: 400.50 \mu \mathrm{l}$ of the mixed cell suspension were applied on glass slides coated with poly-L-lysine. The suspension was allowed to stand for $10 \mathrm{~min}$ at room temperature. After incubation, the slide was dipped in ice cold methanol for $20 \mathrm{~s}$ followed by drying. Using a modified protocol ${ }^{51}$, the slide was stained with $100 \mathrm{\mu g} \mathrm{ml}^{-1}$ acridine orange in $1 \%(\mathrm{v} / \mathrm{v})$ acetic acid for $2 \mathrm{~min}$ followed by gentle washing with deionized water. The cells were visualized using a fluorescence microscope (Axiophot, Carl Zeiss) equipped with suitable filters (excitation at $450-490 \mathrm{~nm}$ and emission at $520 \mathrm{~nm}$ ). The images were recorded using Axiocam ICc1 camera along with the software Zen (blue edition) at a magnification of $1000 \mathrm{x}$.

MALDI-imaging mass spectrometry. The main challenge for microbial MALDIimaging mass spectrometry is to ensure complete contact between the sample and the conductive surface where the measurements take place ${ }^{52}$. While microbes can be cultured on non-disposable MALDI target $\operatorname{slides}^{52}$, we used indium tin oxide (ITO) coated glass slides that allowed storage of samples for several months and reanalysis if needed. Furthermore, our sample preparation method avoids transfer of delicate samples before MALDI-imaging mass spectrometry measurements, and it prevented flaking of the agar layer during the drying step, measurement, and storage.

For mixed cultivation of algae and bacteria, sterilized ITO coated glass slides (Bruker Daltonics) were placed inside petri dishes and overlaid with $3.3 \mathrm{ml} 0.5 \%$ TAP agar containing C. reinhardtii at a density of $\sim 9 \times 10^{5} \mathrm{cells}^{-1} .10 \mu \mathrm{l}$ of $P$. protegens $\left(\sim 1 \times 10^{9}\right.$ cells ml $\left.{ }^{-1}\right)$ washed in TAP medium were then applied to the surface of the solidified agar medium. For comparison, axenic samples were prepared in the same way, but by omitting either algal or bacterial cells. The petri dishes were closed and wrapped with parafilm. The cultures were incubated at $20^{\circ} \mathrm{C}$ and continuous light $\left(50 \mu \mathrm{mol}\right.$ photons $\left.\mathrm{m}^{-2} \mathrm{~s}^{-1}\right)$. After 3 days, the parafilm and any condensed water were removed, and the petri dishes were wrapped with Micropore tape $(3 \mathrm{M})$. In this way, the slides were stored at room temperature for additional 3 days until the agar was dried.

Matrix preparation followed the protocol proposed in Hoffman and Dorrestein, $2015^{53}$. Samples were coated with a saturated solution $\left(20 \mathrm{mg} \mathrm{ml}^{-1}\right)$ of universal MALDI matrix (1:1 mixture of 2,5-dihydroxybenzoic acid [DHB] and $\alpha$-cyano-4hydroxycinnamic acid [HCCA]; Sigma Aldrich) dissolved in ACN/MeOH/ $\mathrm{H}_{2} \mathrm{O}$ $(70: 25: 5, \mathrm{v} / \mathrm{v} / \mathrm{v})$. The matrix was sprayed using the automatic system ImagePrep device 2.0 (Bruker Daltonics) in 60 cycles (2 s spraying, $10 \mathrm{~s}$ incubation time, and $40 \mathrm{~s}$ of active drying using nitrogen gas), rotating the sample $180^{\circ}$ after 30 cycles.

The samples were analyzed in an UltrafleXtreme MALDI TOF/TOF (Bruker Daltonics), which was operated in positive reflector mode using flexControl 3.0. The analysis was performed in two ranges: $0-2000 \mathrm{Da}$ range, with $30 \%$ laser intensity (laser type 3), accumulating 1000 shots by taking 50 random shots at every raster position; and 700-3500 Da range, with $40 \%$ laser intensity (laser type 3), accumulating 1000 shots by taking 50 random shots at every raster position. Raster width was set at $200 \mu \mathrm{m}$. Calibration of the acquisition method was performed externally using Peptide Calibration Standard II (Bruker Daltonics) containing bradykinin 1-7, angiotensin II, angiotensin I, substance $\mathrm{P}$, bombesin, ACTH clip 1-17, ACTH clip 18-39, and somatostatin 28.

In addition, spectra obtained in the $0-2000 \mathrm{Da}$ range were processed with baseline subtraction in flexAnalysis 3.3 and corrected internally using the peaks of HCCA (from the matrix; $[\mathrm{M}+\mathrm{H}]^{+} \mathrm{m} / z 190.0499$ and $[2 \mathrm{M}+\mathrm{H}]^{+} \mathrm{m} / z$ 379.0925). Processed spectra were uploaded in flexImaging 3.0 for visualization and SCILS Lab 2015b for analysis and representation. Chemical images were obtained using total ion count (TIC) normalization and weak denoising.

Extraction of extracellular compounds from $\boldsymbol{P}$. protegens. To prepare spent media extracts for LC-high-resolution MS measurements, starter cultures of $P$. protegens were grown in $5 \mathrm{ml} \mathrm{LB}$ broth in test tubes for $24 \mathrm{~h}$ at $28^{\circ} \mathrm{C}$ and orbital shaking at $200 \mathrm{rpm} . \sim 7 \times 10^{8}$ cells from $0.5 \mathrm{ml}$ of starter culture were washed three times with TAP medium and used to inoculate $250 \mathrm{ml}$ of TAP medium in a 1 liter conical flask. The culture was grown at room temperature with shaking at $110 \mathrm{rpm}$. To prepare cocultures, C. reinhardtii cells were added after $24 \mathrm{~h}$ in a ratio of $1: 100$ (algae to bacteria) and incubated for further $24 \mathrm{~h}$. The cells were removed by centrifugation $\left(20 \mathrm{~min}, 16,000 \times \mathrm{g}, 4^{\circ} \mathrm{C}\right)$. The supernatant was sterile filtrated (CHROMAFIL ${ }^{\circledR}$ CA-20/25 (S), pore size $0.20 \mu \mathrm{m}$ ), extracted three times with ethyl acetate $(250 \mathrm{ml})$, and the extract was dried by rotary evaporation at $40^{\circ} \mathrm{C}$. The dried residue was dissolved in $250 \mu \mathrm{l}$ of methanol (HPLC grade), and the solution passed through a filter with a pore size of $0.45 \mu \mathrm{m}$.

LC-high-resolution MS. The analyses were performed on a Q-Exactive Orbitrap mass spectrometer coupled to an Accela AS LC system (Thermo Fisher, San José, USA). Organic solvents (LC-MS grade) and reagents used for LC-MS analysis were purchased from Sigma Aldrich. An Accucore C18 column $(2.6$ um, $100 \times 2.1 \mathrm{~mm}$; Thermo Fisher) was eluted at $0.2 \mathrm{ml} \mathrm{min}^{-1}$ with water (eluent A) and acetonitrile (eluent B) both containing $0.1 \%$ formic acid. Gradient elution used was: $5-98 \%$ B over $10 \mathrm{~min}$, hold $12 \mathrm{~min}, 98-5 \% \mathrm{~B}$ in $0.1 \mathrm{~min}$, and hold $6.9 \mathrm{~min}$. Injection volume was $10 \mu \mathrm{l}$ and the oven temperature was $30^{\circ} \mathrm{C}$. Pure orfamide A and B (Santa Cruz Biotechnology) was dissolved in methanol/water $(1: 1, v / v)$ to a concentration of $100 \mathrm{ng} \mathrm{ml}^{-1}$. High-resolution full MS experiments (positive ionization) were acquired in the range of $\mathrm{m} / \mathrm{z} 150-2000$. The following source settings were used: spray voltage $=3.5$; capillary temperature $=250^{\circ} \mathrm{C}$; capillary voltage $=50 \mathrm{~V}$; sheath gas flow $=49$ and auxiliary gas flow $=5$ (arbitrary units); tube lens voltage $=130 \mathrm{~V}$. Resolving power was set at 35,000 (FWHM at $\mathrm{m} / z$ 400). For fragmentation experiments, precursors were selected by the quadrupole with an isolation window of $1 \mathrm{Da}$, a target value of $2 \times 10^{5}$, and a maximum ion injection time of $200 \mathrm{~ms}$. Precursor ions were subjected to fragmentation with 18 and 22\% normalized collision energy in the higher energy collisional dissociation (HCD) cell, and the resulting fragment ions were detected in the Orbitrap mass analyzer at a resolution of 70,000 (FWHM at $\mathrm{m} / \mathrm{z} 400$ ).

Aequorin expression and transformation of $\boldsymbol{C}$. reinhardtii. The pHD-AEQ2 vector was used for transformation. Its complete sequence is shown in Supplementary Fig. 7. This vector carries a codon optimized apo-aequorin gene ${ }^{27}$ that was synthesized by GeneArt Life Technologies. The apo-aequorin gene was put under control of the HSP7OA/RBCS2 tandem promoter along with the first intron of $R B C S 2^{54}$ and was set in front of the RACK1 $3^{\prime}$-UTR representing a constitutive reference transcript ${ }^{55}$. The vector also carries the hygromycin $B$ resistance from the Hyg 3 vector ${ }^{56}$ for selection in C. reinhardtii as well as an ampicillin resistance (selection marker for E. coli). C. reinhardtii wild-type cells (strain SAG 73.72) were transformed with the autolysin method as described earlier ${ }^{57}$. SAG 73.72 cells were transformed with either pHyg3 (vector control) or pHD-AEQ2 (AEQ lines). Hygromycin-resistant colonies were further examined in immunoblots (see below) for expression of apo-aequorin. 
Crude extract and immunoblotting. Preparation of crude extracts to detect the apo-aequorin protein was done as described ${ }^{57}$. For immunoblotting, $50 \mu \mathrm{g}$ of proteins of a crude extract from cells harvested in the middle of the day were separated by $10 \%$ SDS-PAGE and the proteins were transferred to a polyvinylidine difluoride (PVDF) membrane. Blocking and detection was done as published before $^{58}$. The primary antibody used for immunoblotting was anti-aequorin (Covalab, France); it was used at a dilution of 1:2000 in the blocking solution. The secondary antibody was anti-rabbit antibody conjugated to horseradish peroxidase used at a dilution of 1:6666 (Sigma Aldrich). Full blots and stained membranes are presented in Supplementary Fig. 14.

Intracellular $\mathrm{Ca}^{2+}$ measurement using an aequorin reporter. Cells expressing apo-aequorin (SAG 73.72::pHD-AEQ2, abbreviated as AEQ cells) as well as the control cells used for the $\mathrm{Ca}^{2+}$ measurement were grown in TAP medium for $72 \mathrm{~h}$ up to a cell density of $3-4 \times 10^{6}$ cells ml ${ }^{-1}$. The cells were counted using a Thoma cell counting chamber. Prior to the $\mathrm{Ca}^{2+}$ measurement, $1 \mathrm{ml}$ of cells were incubated together with $23 \mu \mathrm{M}$ of coelenterazine (Synchem, Germany) in the dark for $2 \mathrm{~h}$ at room temperature. For the measurement, 96 well plates (white with clear bottom, Berthold technologies \#60705) were used. Each well was loaded with $100 \mu \mathrm{l}$ of coelenterazine-treated cell suspension. The microplate luminometer (LB-941, Mithras Berthold Technologies) was used for the luminescence measurement. The machine was programmed using the software Mikrowin2000 (provided by the manufacturer). The counting time was set between 0.2 and $1 \mathrm{~s}$ and the delay between each count was set between 5 and $7 \mathrm{~s}$. For measuring the $\mathrm{Ca}^{2+}$ elevation under the influence of $20 \mathrm{mM} \mathrm{CaCl}_{2}, 190 \mu \mathrm{l}$ of cells (AEQ22, AEQ24, AEQ33, or AEQ34) incubated with coelenterazine were loaded in a 96 well microplate; after measurement of background, $10 \mu \mathrm{l}$ of $400 \mathrm{mM} \mathrm{CaCl}_{2}$ solution was injected followed by RLU measurement for $300 \mathrm{~s}$. Maximal luminescence (full discharge) was determined by adding $100 \mu \mathrm{l}$ of discharge solution $\left(2 \mathrm{M} \mathrm{CaCl}_{2}, 10 \%\right.$ ethanol) to each well ${ }^{59}$. Obtained relative luminescence unit (RLU) values were exported to Microsoft Excel and values were converted to molar $\mathrm{Ca}^{2+}$ concentrations using the equation $\mathrm{pCa}=0.332588(-\log k)+5.5593$ as in ref. ${ }^{59}$.

Induction of pH and salt stress. Acid-induced deflagellation was done as described $^{26} .100 \mu \mathrm{l}$ of $40 \mathrm{mM}$ sodium acetate, $\mathrm{pH} 4.5(40 \mathrm{mM}$ sodium acetate, $\mathrm{pH}$ adjusted using acetic acid) were added to $100 \mu \mathrm{l}$ coelenterazine pretreated AEQ34 cells in HEPES buffer (10 mM HEPES, pH 7.4, $1 \mathrm{mM} \mathrm{CaCl}_{2}, 50 \mu \mathrm{M}$ $\mathrm{MgCl}_{2}$, and $1 \mathrm{mM} \mathrm{KCl}$ ). For salt stress measurements, $100 \mu \mathrm{l}$ of $\mathrm{NaCl}$ (in $\mathrm{ddH}_{2} \mathrm{O}$ ) were added to $100 \mu \mathrm{l}$ of AEQ34 cells to reach a final concentration of 100,200 , or $300 \mathrm{mM}$.

$\mathrm{Ca}^{2+}$ measurement under the influence of orfamide $\mathrm{A}$ and $\mathrm{B}$. Algal cells were grown in TAP medium for $72 \mathrm{~h}$, the cell density was adjusted to $4 \times 10^{6} \mathrm{cells} \mathrm{ml}^{-1}$, and then the cells were pre-incubated with coelenterazine. P. protegens was grown in LB medium overnight. Orfamide A or B (Santa Cruz Biotechnology) were dissolved in methanol. For the $\mathrm{Ca}^{2+}$ measurement, this stock solution was diluted in $100 \mu \mathrm{l}$ of TAP medium before commencing the measurement. To block the $\mathrm{Ca}^{2+}$ channels in the plasma membrane, $\mathrm{AEQ} 34$ cells grown in TAP medium were suspended in HEPES buffer (see above) after washing the cells three times with the same. Overall, $20 \mu \mathrm{M}$ lanthanum chloride $\left(\mathrm{LaCl}_{3}\right)$ was added to the cells before starting the experiment in the 96 well microplate. For preparing TAP medium lacking $\mathrm{Ca}^{2+}$, the salt solution mix for TAP deficient of calcium chloride was used.

Deflagellation and Evans blue staining. Cells were taken at a cell density of $3-4 \times 10^{6}$ cells ml $^{-1}$. For Evans blue staining, the cells were treated with 10 or 35 $\mu \mathrm{M}$ of orfamide $\mathrm{A}, 10 \mu \mathrm{M}$ orfamide B, or $10 \mu \mathrm{M}$ of mastoparan (Sigma Aldrich, product number M5280) for $30 \mathrm{~s}$ followed by brief washing three times for $10 \mathrm{~s}$ with TAP medium at room temperature. As control, the samples were treated with an equivalent volume of methanol for orfamides and water in the case of mastoparan. After washing the cells, they were resuspended in $0.1 \%(\mathrm{w} / \mathrm{v})$ Evans blue stain in TAP medium for $5 \mathrm{~min}$ followed by microscopy and cell counting. For deflagellation studies, the cells were treated in similar manner mentioned above, but the washing steps were skipped as the cells were fixed with $4-8 \%(\mathrm{v} / \mathrm{v})$ potassium iodide after treatment with orfamide and mastoparan. The cells were imaged using DIC microscopy (Axioplan 2 from Zeiss), and counting was performed using Image J (Version 1.48) cell counter.

Data availability. The datasets generated during and/or analyzed during the current study are available from the corresponding authors on reasonable request. Plasmids and transgenic lines are available from MM on basis of a Material Transfer Agreement.

Received: 10 February 2017 Accepted: 27 September 2017 Published online: 24 November 2017

\section{References}

1. Field, C. B., Behrenfeld, M. J., Randerson, J. T. \& Falkowski, P. Primary production of the biosphere: integrating terrestrial and oceanic components. Science 281, 237-240 (1998).

2. Kusari, S., Hertweck, C. \& Spiteller, M. Chemical ecology of endophytic fungi: origins of secondary metabolites. Chem. Biol. 19, 792-798 (2012).

3. Jung, S. W., Kim, B. H., Katano, T., Kong, D. S. \& Han, M. S. Pseudomonas fluorescens HYK0210-SK09 offers species-specific biological control of winter algal blooms caused by freshwater diatom Stephanodiscus hantzschii. J. Appl. Microbiol. 105, 186-195 (2008).

4. Leão, P. N. et al. Synergistic allelochemicals from a freshwater cyanobacterium. Proc. Natl. Acad. Sci. USA 107, 11183-11188 (2010).

5. Paul, C. \& Pohnert, G. Interactions of the algicidal bacterium Kordia algicida with diatoms: regulated protease excretion for specific algal lysis. PLoS ONE 6 , e21032 (2011).

6. Seyedsayamdost, M. R., Case, R. J., Kolter, R. \& Clardy, J. The Jekyll-and-Hyde chemistry of Phaeobacter gallaeciensis. Nat. Chem. 3, 331-335 (2011).

7. Demuez, M., Gonzalez-Fernandez, C. \& Ballesteros, M. Algicidal microorganisms and secreted algicides: new tools to induce microalgal cell disruption. Biotechnol. Adv. 33, 1615-1625 (2015).

8. Hom, E. F., Aiyar, P., Schaeme, D., Mittag, M. \& Sasso, S. A chemical perspective on microalgal-microbial interactions. Trends Plant Sci. 20, 689-693 (2015).

9. Merchant, S. S. et al. The Chlamydomonas genome reveals the evolution of key animal and plant functions. Science 318, 245-250 (2007).

10. Blaby, I. K. et al. The Chlamydomonas genome project: a decade on. Trends Plant Sci. 19, 672-680 (2014).

11. Jinkerson, R. E. \& Jonikas, M. C. Molecular techniques to interrogate and edit the Chlamydomonas nuclear genome. Plant J. 82, 393-412 (2015)

12. Petroutsos, D. et al. A blue-light photoreceptor mediates the feedback regulation of photosynthesis. Nature 537, 563-566 (2016).

13. Schmidts, M. et al. TCTEX1D2 mutations underlie Jeune asphyxiating thoracic dystrophy with impaired retrograde intraflagellar transport. Nat. Commun. 6 , 7074 (2015).

14. Delucca, R. \& McCracken, M. D. Observations on interactions between naturally-collected bacteria and several species of algae. Hydrobiologia $\mathbf{5 5}$ 71-75 (1977)

15. Kazamia, E. et al. Mutualistic interactions between vitamin $B_{12}$-dependent algae and heterotrophic bacteria exhibit regulation. Environ. Microbiol. 14, 1466-1476 (2012).

16. Hom, E. F. Y. \& Murray, A. W. Niche engineering demonstrates a latent capacity for fungal-algal mutualism. Science 345, 94-98 (2014).

17. Ramette, A. et al. Pseudomonas protegens sp. nov., widespread plant-protecting bacteria producing the biocontrol compounds 2,4-diacetylphloroglucinol and pyoluteorin. Syst. Appl. Microbiol. 34, 180-188 (2011).

18. Hol, W. H., Bezemer, T. M. \& Biere, A. Getting the ecology into interactions between plants and the plant growth-promoting bacterium Pseudomonas fluorescens. Front. Plant Sci. 4, 81 (2013).

19. Lim, C. K., Hassan, K. A., Tetu, S. G., Loper, J. E. \& Paulsen, I. T. The effect of iron limitation on the transcriptome and proteome of Pseudomonas fluorescens Pf-5. PLoS ONE 7, e39139 (2012).

20. Lim, C. K., Hassan, K. A., Penesyan, A., Loper, J. E. \& Paulsen, I. T. The effect of zinc limitation on the transcriptome of Pseudomonas fluorescens Pf-5. Environ. Microbiol. 15, 702-715 (2013).

21. Loper, J. E. \& Gross, H. Genomic analysis of antifungal metabolite production by Pseudomonas fluorescens Pf-5. Eur. J. Plant Pathol. 119, 265-278 (2007).

22. Esquenazi, E., Yang, Y. L., Watrous, J., Gerwick, W. H. \& Dorrestein, P. C. Imaging mass spectrometry of natural products. Nat. Prod. Rep. 26, 1521-1534 (2009).

23. Graupner, K. et al. Imaging mass spectrometry and genome mining reveal highly antifungal virulence factor of mushroom soft rot pathogen. Angew. Chem. Int. Ed. Engl. 51, 13173-13177 (2012).

24. Stasulli, N. M. \& Shank, E. A. Profiling the metabolic signals involved in chemical communication between microbes using imaging mass spectrometry. FEMS Microbiol. Rev. 40, 807-813 (2016).

25. Hassan, K. A. et al. Inactivation of the GacA response regulator in Pseudomonas fluorescens Pf-5 has far-reaching transcriptomic consequences. Environ. Microbiol. 12, 899-915 (2010).

26. Wheeler, G. L., Joint, I. \& Brownlee, C. Rapid spatiotemporal patterning of cytosolic $\mathrm{Ca}^{2+}$ underlies flagellar excision in Chlamydomonas reinhardtii. Plant J. 53, 401-413 (2008)

27. Inouye, S. et al. Cloning and sequence analysis of cDNA for the luminescent protein aequorin. Proc. Natl. Acad. Sci. USA 82, 3154-3158 (1985).

28. Braun, F. J. \& Hegemann, P. Direct measurement of cytosolic calcium and $\mathrm{pH}$ in living Chlamydomonas reinhardtii cells. Eur. J. Cell Biol. 78, 199-208 (1999).

29. Quarmby, L. M. \& Hartzell, H. C. Two distinct, calcium-mediated, signal transduction pathways can trigger deflagellation in Chlamydomonas reinhardtii. J. Cell Biol. 124, 807-815 (1994). 
30. Bickerton, P., Sello, S., Brownlee, C., Pittman, J. K. \& Wheeler, G. L. Spatial and temporal specificity of $\mathrm{Ca}^{2+}$ signalling in Chlamydomonas reinhardtii in response to osmotic stress. New Phytol. 212, 920-933 (2016).

31. Gross, H. et al. The genomisotopic approach: a systematic method to isolate products of orphan biosynthetic gene clusters. Chem. Biol. 14, 53-63 (2007).

32. Gross, H. \& Loper, J. E. Genomics of secondary metabolite production by Pseudomonas spp. Nat. Prod. Rep. 26, 1408-1446 (2009).

33. Yordanova, Z. P., Woltering, E. J., Kapchina-Toteva, V. M. \& Iakimova, E. T. Mastoparan-induced programmed cell death in the unicellular alga Chlamydomonas reinhardtii. Ann. Bot. 111, 191-205 (2013).

34. Hilton, L. K. et al. A forward genetic screen and whole genome sequencing identify deflagellation defective mutants in Chlamydomonas, including assignment of ADF1 as a TRP channel. G3 6, 3409-3418 (2016).

35. Knight., H., Trewavas, J. \& Knight, M. R. Calcium signalling in Arabidopsis thaliana responding to drought and salinity. Plant J. 12, 1067-1078 (1997).

36. Trempel, F. et al. Altered glycosylation of exported proteins, including surface immune receptors, compromises calcium and downstream signaling responses to microbe-associated molecular patterns in Arabidopsis thaliana. BMC Plant Biol. 16, 31 (2016).

37. Falciatore, A., d'Alcala, M. R., Croot, P. \& Bowler, C. Perception of environmental signals by a marine diatom. Science 288, 2363-2366 (2000).

38. Vardi, A. et al. A stress surveillance system based on calcium and nitric oxide in marine diatoms. PLoS Biol. 4, e60 (2006).

39. Hegemann, P. \& Berthold, P. in The Chlamydomonas Sourcebook 2nd edn (eds Harris, E.A., Stern, D. B. \& Witman, G. B.) 395-429 (Academic, Oxford, 2009).

40. Verret, F., Wheeler, G., Taylor, A. R., Farnham, G. \& Brownlee, C. Calcium channels in photosynthetic eukaryotes: implications for evolution of calciumbased signaling. New Phytol. 187, 23-43 (2010).

41. Müller, A. et al. Daptomycin inhibits cell envelope synthesis by interfering with fluid membrane microdomains. Proc. Natl. Acad. Sci. USA 113, E7077-E7086 (2016).

42. Lee, B.-G. et al. Structures of $\mathrm{ClpP}$ in complex with acyldepsipeptide antibiotics reveal its activation mechanism. Nat. Struct. Mol. Biol. 17, 471-479 (2010).

43. Ma, Z. et al. Biosynthesis, chemical structure, and structure-activity relationship of orfamide lipopeptides produced by Pseudomonas protegens and related species. Front. Microbiol. 7, 382 (2016).

44. Kim, J.-D., Kim, B. \& Lee, C.-G. Alga-lytic activity of Pseudomonas fluorescens against the red tide causing marine alga Heterosigma akashiwo (Raphidophyceae). Biol. Control 41, 296-303 (2007).

45. Znachor, P. \& Jezberová, J. The occurrence of a bloom-forming green alga Pleodorina indica (Volvocales) in the downstream reach of the River Malše (Czech Republic). Hydrobiologia 541, 221-228 (2005).

46. Choi, J.-C. \& Tiedje, J. M. Biogeography and degree of endemicity of fluorescent Pseudomonas strains in soil. Appl. Environ. Microbiol. 66, 5448-5456 (2005).

47. Harris, E. H. (ed.). The Chlamydomonas Sourcebook (Academic, San Diego, CA, 1989)

48. McBride, M. J. et al. Novel features of the polysaccharide-digesting gliding bacterium Flavobacterium johnsoniae as revealed by genome sequence analysis. Appl. Environ. Microbiol. 75, 6864-6875 (2009).

49. Da Silva, A. C. et al. Comparison of the genomes of two Xanthomonas pathogens with differing host specificities. Nature 417, 459-463 (2002).

50. Paulsen, I. T. et al. Complete genome sequence of the plant commensal Pseudomonas fluorescensPf-5. Nat. Biotechnol. 23, 873-878 (2005).

51. McCarthy, L. R. \& Senne, J. E. Evaluation of acridine orange stain for detection of microorganisms in blood cultures. J. Clin. Microbiol. 11, 281-285 (1980).

52. Yang, J. Y. et al. Primer on agar-based microbial imaging mass spectrometry. J. Bacteriol. 194, 6023-6028 (2012).

53. Hoffmann, T. \& Dorrestein, P. C. Homogeneous matrix deposition on dried agar for MALDI imaging mass spectrometry of microbial cultures. J. Am. Soc. Mass Spectrom. 26, 1959-1962 (2015).

54. Sizova, I., Fuhrmann, M. \& Hegemann, P. A. Streptomyces rimosus aphVIII gene coding for a new type phosphotransferase provides stable antibiotic resistance to Chlamydomonas reinhardtii. Gene 277, 221-229 (2001).
55. Mus, F., Dubini, A., Seibert, M., Posewitz, M. C. \& Grossman, A. R. Anaerobic acclimation in Chlamydomonas reinhardtii: anoxic gene expression, hydrogenase induction, and metabolic pathways. J. Biol. Chem. 282 25475-25486 (2007).

56. Berthold, P., Schmitt, R. \& Mages, W. An engineered Streptomyces hygroscopicus aph 7 " gene mediates dominant resistance against hygromycin $\mathrm{B}$ in Chlamydomonas reinhardtii. Protist 153, 401-412 (2002).

57. Iliev, D. et al. A heteromeric RNA-binding protein is involved in maintaining acrophase and period of the circadian clock. Plant Physiol. 142, 797-806 (2006).

58. Beel, B. et al. A flavin binding cryptochrome photoreceptor responds to both blue and red light in Chlamydomonas reinhardtii. Plant Cell 24, 2992-3008 (2012).

59. Knight, H., Trewavas, A. J. \& Knight, M. R. Cold calcium signaling in Arabidopsis involves two cellular pools and a change in calcium signature after acclimation. Plant Cell 8, 489-503 (1996).

\section{Acknowledgements}

P.A., D.S., M.G.-A., C.H., S.S., and M.M. are grateful for financial support from the Deutsche Forschungsgemeinschaft (DFG) for Grant SFB 1127 (ChemBioSys). H.D. and M.M. are thankful for DFG Grant Mi 373-10 and M.G.-A. for an ERC grant for a Marie Skłodowska-Curie Individual Fellowship (IF-EF, Project Reference 700036). P.A. has a fellowship from the International Leibniz Research School ILRS (Project Number 321020) in Jena and D.C.F. from the Jena School for Microbial Communication JSMC P.A. and D.S. are PhD students associated with the JSMC. We thank U. Holtzegel for her suggestion to use the aequorin reporter to study algal-bacterial interactions; A. Mrozinska and R. Oelmüller for advice with the aequorin assay, M. Wich for her help with the vector control transformation, C. Wilhelm for providing Pedinomonas minor as well as H. Gross, J.E. Loper, and B.T. Shaffer for providing the $\Delta$ of $a A$ mutant. We are grateful to K. Dunbar and E. Molloy for proofreading the manuscript and valuable comments.

\section{Author contributions}

C.H., S.S., and M.M. designed the experiments. P.A., D.S., M.G.-A., D.C.F., and H.D conducted the experiments. P.A., D.S., M.G.-A., D.C.F., C.H., S.S., and M.M. wrote the article.

\section{Additional information}

Supplementary Information accompanies this paper at doi:10.1038/s41467-017-01547-8.

Competing interests: The authors declare no competing financial interests.

Reprints and permission information is available online at http://npg.nature.com/ reprintsandpermissions/

Publisher's note: Springer Nature remains neutral with regard to jurisdictional claims in published maps and institutional affiliations.

\begin{abstract}
Open Access This article is licensed under a Creative Commons Attribution 4.0 International License, which permits use, sharing, adaptation, distribution and reproduction in any medium or format, as long as you give appropriate credit to the original author(s) and the source, provide a link to the Creative Commons license, and indicate if changes were made. The images or other third party material in this article are included in the article's Creative Commons license, unless indicated otherwise in a credit line to the material. If material is not included in the article's Creative Commons license and your intended use is not permitted by statutory regulation or exceeds the permitted use, you will need to obtain permission directly from the copyright holder. To view a copy of this license, visit http://creativecommons.org/ licenses/by/4.0/.
\end{abstract}

(C) The Author(s) 2017 